OPEN ACCESS

Edited by:

Jyoti Prakash Tamang,

Sikkim University, India

Reviewed by:

Analia Graciela Abraham,

Centro de Investigación y Desarrollo en Criotecnología de Alimentos, Argentina

Baltasar Mayo

Consejo Superior de Investigaciones

Científicas, Spain

*Correspondence:

Paul D. Cotter

paul.cotter@teagasc.ie

Specialty section:

This article was submitted to

Food Microbiology,

a section of the journal

Frontiers in Microbiology

Received: 11 March 2016

Accepted: 18 April 2016

Published: 04 May 2016

Citation:

Bourrie BCT, Willing BP and Cotter PD

(2016) The Microbiota and Health Promoting Characteristics of the

Fermented Beverage Kefir.

Front. Microbiol. 7:647.

doi: 10.3389/fmicb.2016.00647

\section{The Microbiota and Health Promoting Characteristics of the Fermented Beverage Kefir}

\author{
Benjamin C. T. Bourrie ${ }^{1,2}$, Benjamin P. Willing ${ }^{1}$ and Paul D. Cotter ${ }^{2,3 *}$ \\ ${ }^{1}$ Agricultural, Food and Nutritional Sciences, University of Alberta, Edmonton, AB, Canada, ${ }^{2}$ Teagasc Food Research \\ Centre, Fermoy, Ireland, ${ }^{3}$ APC Microbiome Institute, Cork, Ireland
}

Kefir is a complex fermented dairy product created through the symbiotic fermentation of milk by lactic acid bacteria and yeasts contained within an exopolysaccharide and protein complex called a kefir grain. As with other fermented dairy products, kefir has been associated with a range of health benefits such as cholesterol metabolism and angiotensin-converting enzyme (ACE) inhibition, antimicrobial activity, tumor suppression, increased speed of wound healing, and modulation of the immune system including the alleviation of allergy and asthma. These reports have led to increased interest in kefir as a focus of research and as a potential probiotic-containing product. Here, we review those studies with a particular emphasis on the microbial composition and the health benefits of the product, as well as discussing the further development of kefir as an important probiotic product.

Keywords: gut microbiota, fermented foods, immunomodulation, metabolic diseases, kefir

\section{INTRODUCTION}

Fermented dairy products have long been associated with the ability to confer health benefits in those who regularly consume them, with Ellie Metchnikoff first theorizing that their impact on the bacterial microbiota in the gut contributed to health and long life (Metchnikoff, 1908). Indeed many reportedly probiotic-containing foods come in the form of fermented milk products, such as yogurt, koumis, and kefir, many of which have been consumed for 100s of years (Tamime, 2002; Parvez et al., 2006). Probiotics are live microorganisms which, when administered in adequate amounts, confer a health benefit on the host (Hill et al., 2014). As is the case with the fermented dairy products referred to above, probiotics are consumed in foods containing these organisms in sufficiently large quantities to pass safely to the gastrointestinal tract but can also come in the form of supplements consisting of live organisms such as pills.

Although not as widely popular as other fermented dairy products, such as yogurt and cheese, kefir has been consumed and associated with health benefits for 100s of years; originally by communities in the Caucasian mountains. The beverage itself typically has a slightly viscous texture with tart and acidic flavor, low levels of alcohol, and in some cases slight carbonation. Kefir is traditionally made with cow's milk but it can be made with milk from other sources such as goat, sheep, buffalo, or soy milk (Ismail et al., 1983; Motaghi et al., 1997; Wszolek et al., 2001; Liu et al., 2006a). One of the features that distinguish kefir from many other fermented dairy products is the requirement for the presence of a kefir grain in fermentation and the presence and importance of a large population of yeasts (Tamime, 2002; Tamang et al., 2016). The aforementioned kefir grains are microbially derived protein and polysaccharide matrices that contain a community of 
bacterial and fungal species that are essential to kefir fermentation (Garrote et al., 2001; Marsh et al., 2013). Traditionally, fermentation was initiated through the addition of kefir grains, which originally formed during the fermentation of milk, to unfermented milk in a sheep or goat skin bag (Motaghi et al., 1997). Commercial, industrial-scale production rarely utilizes kefir grains for fermentation, but rather uses starter cultures of microbes that have been isolated from kefir or kefir grains in order to provide more consistent products (Assadi et al., 2000). While this industrially produced kefir may have health benefits of its own, research examining such benefits has either not been performed or is not published. Thus, any kefir referred to in this review has been produced in a traditional manner using kefir grains or grain fermented milk as the inoculum. In addition to the microbial population present in kefir, these beverages typically also contain an abundance of fermentation products such as organic acids and multiple volatile flavor compounds including ethanol, acetaldehyde, and diacetyl (Güzel-Seydim et al., 2000). As part of the fermentation process, an exopolysaccharide unique to kefir, kefiran, is produced. Kefiran makes up a large proportion of the kefir grain itself and is also found dissolved in the liquid phase, where it contributes to the rheology and texture of the finished product (La Rivière et al., 1967; Frengova et al., 2002; Rimada and Abraham, 2006).

In this review we will discuss the many health promoting effects that have been attributed to kefir, including tumor suppression and prevention, gastrointestinal immunity and allergy, wound healing, cholesterol assimilation and ACE inhibition, its antimicrobial properties, and the ability of kefir to modify the composition and activity of the gut microbiota (Figure 1).

\section{BACTERIAL AND FUNGAL POPULATIONS OF KEFIR}

\section{Bacterial Populations}

Since the first established use, 100s of years ago, the propagation of kefir has been performed by transferring kefir grains from one batch to fresh milk and incubating at ambient temperature. Over this period there has been substantial opportunity for the microbial component of kefir grains to evolve and diverge, resulting in the addition or loss of bacteria and yeasts as well as the addition and loss of genes. The bacterial genera most commonly found in kefir using culture dependent techniques are Lactobacillus, Lactococcus, Streptococcus, and Leuconostoc (Simova et al., 2002; Witthuhn et al., 2004; Chen et al., 2008). These genera tend to dominate the population present in both the kefir grain and milk, with Lactococcus lactis subsp. lactis, Streptococcus thermophilus, Lactobacillus delbrueckii subsp. bulgaricus, Lactobacillus helveticus, Lactobacillus casei subsp. pseudoplantarum, Lactobacillus kefiri, Lactobacillus kefir, and Lactobacillus brevis accounting for between 37 and $90 \%$ of the total microbial community present (Simova et al., 2002; Witthuhn et al., 2004; Miguel et al., 2010). While these species commonly make up the majority of the microbial population present in kefir grains, some grains are dominated by yeast species or other bacterial species such as Leuconostoc mesenteroides (Witthuhn et al., 2004). The proportions of species can also differ between the grain and milk (Figure 2). For example, L. lactis subsp. lactis, and S. thermophilus levels are generally much greater in the fermented kefir than in the kefir grains. The levels of these species increase further in kefir made from kefir as an inoculum. Indeed, the total increase observed

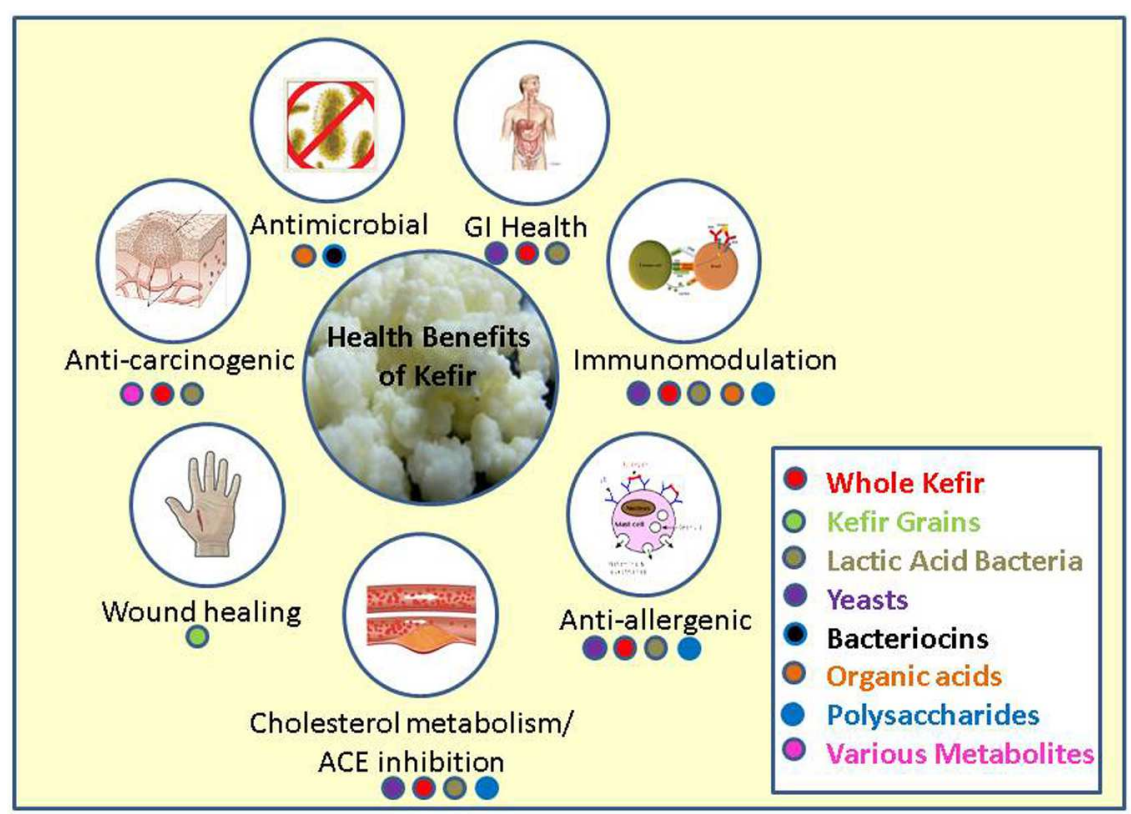

FIGURE 1 | Major health benefits associated with kefir and the fractions or parts of kefir responsible for these benefits. 


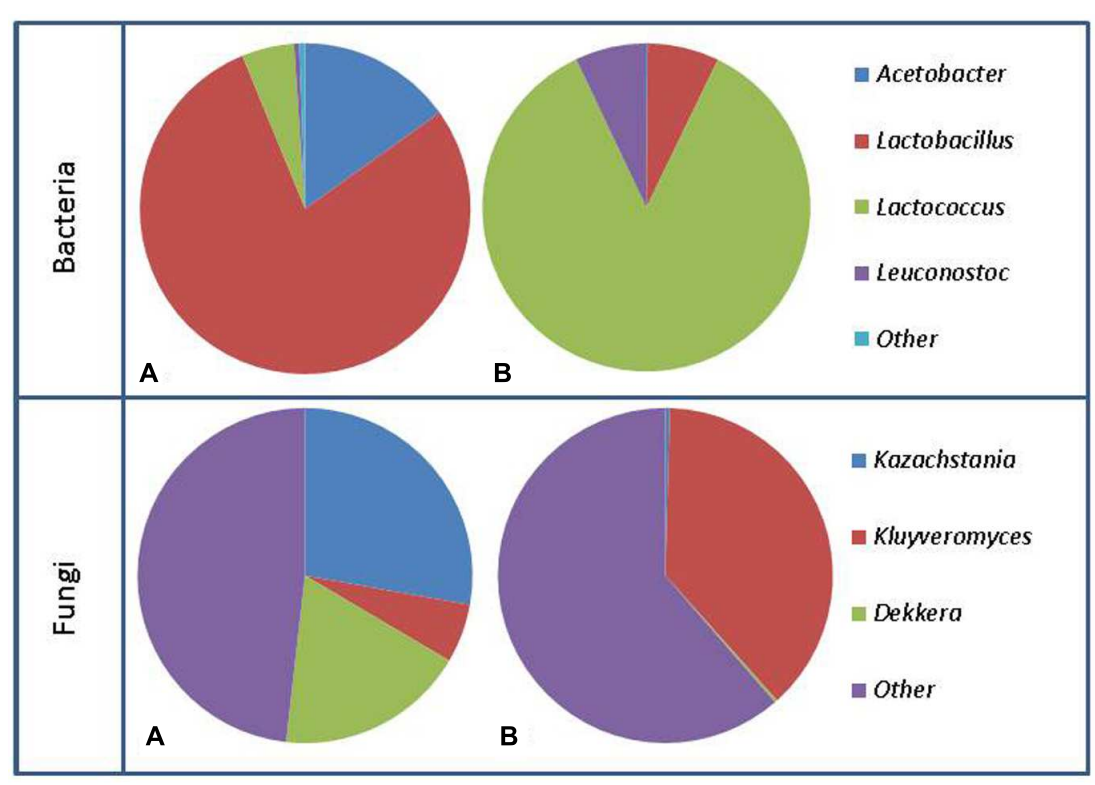

FIGURE 2 | Representation of bacterial population changes from kefir grain (A) to fermented milk (B) and fungal population changes from kefir grain (A) to fermented milk (B). Figure generated using data from Marsh et al. (2013).

has been as much as $30 \%$ in some cases (Simova et al., 2002). The reason for this increase during fermentation in the milk may be due to an increase in temperature created by the active fermentation or simply due to where these bacteria reside in the kefir grain, as organisms such as Lactobacillus may tend to reside deeper within the kefir grain, thus making it harder for them to escape in to the milk.

In agreement with the majority of culture base studies, investigation of the microbial composition of diverse kefir grains using culture independent techniques found that the overall bacterial populations were for the most part dominated by Firmicutes and Proteobacteria, and kefir milk contained a much higher level of representatives of the Streptococcaceae than any other family, (Dobson et al., 2011; Marsh et al., 2013). Based on high-throughput sequencing of $16 \mathrm{~S}$ genes present in kefir grains and milk, it was established that kefir grains typically have 1 (Lactobacillus) or 2 (Lactobacillus and Acetobacter) dominant bacterial genera (Marsh et al., 2013; Nalbantoglu et al., 2014; Garofalo et al., 2015; Korsak et al., 2015). The most common species of Lactobacillus have been L. kefiranofaciens, L. kefiri, and L. parakefiri (Dobson et al., 2011; Leite et al., 2012; Hamet et al., 2013; Vardjan et al., 2013; Nalbantoglu et al., 2014; Garofalo et al., 2015; Korsak et al., 2015). There are many other genera present in these grains; however, they typically represent less than $10 \%$ of the community (Leite et al., 2012; Marsh et al., 2013; Nalbantoglu et al., 2014; Garofalo et al., 2015). When milk fermented by these same grains was examined, the relative abundance of the genera present vary much more than in the grain, with Leuconostoc, Lactococcus, Lactobacillus, and Acetobacter being the most abundant (Marsh et al., 2013; Korsak et al., 2015). As has previously been stated, bacteria found at lower abundance in the kefir grain can become dominant, as species such as Lactococcus are minimally represented in kefir grain, but regularly become the most abundant genus present in the kefir milk (Dobson et al., 2011; Marsh et al., 2013). This observation is consistent with past culture based work, where Lactococcus was found to increase through the fermentation process (Simova et al., 2002). At the species level, high throughput $16 \mathrm{~S}$ analysis showed the number of OTUs vary from 24 to 56 in the kefir grain, and 22 to 61 in kefir milk, i.e., much higher than what has been observed utilizing culture dependent techniques (Marsh et al., 2013). These findings highlight the need for future studies to examine the kefir grain and fermented milk rather than the previous tendency to focus solely on the population of the grain.

With respect to the non-lactic acid bacteria (LAB) that have been associated with kefir, it is notable that culture independent methods have revealed Acetobacter as one of the dominant genera present in grains. This is of interest as Acetobacter is not commonly isolated from kefir via culture dependent techniques and, indeed, has been described as a non-essential contaminant of kefir (Angulo et al., 1993; Pintado et al., 1996; Rea et al., 1996; Witthuhn et al., 2004). While there are some studies that have found acetic acid bacteria in large quantities in kefir grains (Rea et al., 1996), many rely on isolation media that is not optimal for growth of acetic acid bacteria without further tests in order to gather an accurate identification (Witthuhn et al., 2005). Bifidobacterium species have also been identified through culture independent studies, however, Bifidobacterium has not been found in any culture based studies of the kefir microbiota (Dobson et al., 2011; Taş et al., 2012; Marsh et al., 2013). Table 1 contains a complete list of bacterial species found in both culture dependent and culture independent studies, while Figure 3 provides a breakdown of the distribution of species found in these studies. 
TABLE 1 | List of bacterial and fungal species found in kefir grains and milk using both culture dependent and culture independent techniques.

Microbial species

\section{Lactobacillus}

Lactobacillus kefir

Lactobacillus kefiranofaciens

Lactobacillus delbrueckii

Lactobacillus helveticus

Lactobacillus casei

Lactobacillus kefiri

Lactobacillus brevis

Lactobacillus paracasei

Lactobacillus parakefir

Lactobacillus plantarum

Lactobacillus satsumensis

Lactobacillus curvatis

Lactobacillus fermentum

Lactobacillus viridescens

Lactobacillus acidophilus

Lactobacillus gasseri

Lactobacillus kefirgranum

Lactobacillus parakefiri

Lactobacillus parabuchneri

Lactobacillus garvieae

Lactobacillus buchneri

Lactobacillus sunkii

Lactobacillus crispatus

Lactobacillus otakiensis

Lactobacillus instestinalis

Lactobacillus amylovorus, L. pentosus,

L. salivarius, L. johnsonii, L. rhamnosus,

L. rossiae, L. sakei, L. reuteri,

L. kalixensis, L. rapi, L. diolivorans,

L. parafarraginis,

L. gallinarum, Pediococcus claussenii,

P. damnosus, P. halophilus,

$P$. pentosaceus, $P$. Iolii

\section{Lactococcus/Streptococcus}

Lactococcus lactis subsp. lactis

Lactococcus lactis subsp. cremoris

Lactococcus lactis subsp. lactis biovar diacetylactis

Lactococcus garvieae

Streptococcus salivarius subsp.

thermophilus

Streptococcous thermophilus

Streptococcus durans

\section{Leuconostoc/Oenococcus}

\section{Leuconostoc spp.}

Leuconostoc mesenteroides subsp. mesenteroides

Leuconostoc mesenteroides subsp. cremoris

Leuconostoc mesenteroides

Leuconostoc pseudomesenteroides

Oenococcus oeni

\section{Reference}

Angulo et al., 1993; Pintado et al., 1996; Garrote et al., 2001; Santos et al., 2003; Mainville et al., 2006; Miguel et al., 2010 Santos et al., 2003; Mainville et al., 2006; Chen et al., 2008; Dobson et al., 2011; Hamet et al., 2013; Vardjan et al., 2013; Nalbantoglu et al., 2014; Garofalo et al., 2015; Korsak et al., 2015; Zanirati et al., 2015 Simova et al., 2002; Santos et al., 2003; Witthuhn et al., 2004; Nalbantoglu et al., 2014 Simova et al., 2002; Chen et al., 2008; Dobson et al., 2011; Nalbantoglu et al., 2014 Angulo et al., 1993; Simova et al., 2002; Nalbantoglu et al., 2014; Zanirati et al., 2015

Chen et al., 2008; Miguel et al., 2010; Dobson et al., 2011; Hamet et al., 2013; Vardjan et al., 2013; Nalbantoglu et al., 2014; Garofalo et al., 2015; Korsak et al., 2015; Zanirati et al., 2015

Angulo et al., 1993; Simova et al., 2002; Santos et al., 2003; Witthuhn et al., 2005; Nalbantoglu et al., 2014

Santos et al., 2003; Miguel et al., 2010; Hamet et al., 2013; Nalbantoglu et al., 2014

Takizawa et al., 1994; Garrote et al., 2001; Miguel et al., 2010

Garrote et al., 2001; Santos et al., 2003; Miguel et al., 2010; Nalbantoglu et al., 2014

Miguel et al., 2010; Zanirati et al., 2015

Witthuhn et al., 2004

Angulo et al., 1993; Witthuhn et al., 2004, 2005

Angulo et al., 1993

Angulo et al., 1993; Santos et al., 2003; Dobson et al., 2011; Nalbantoglu et al., 2014

Angulo et al., 1993; Nalbantoglu et al., 2014

Takizawa et al., 1994; Vardjan et al., 2013

Dobson et al., 2011; Hamet et al., 2013; Vardjan et al., 2013; Nalbantoglu et al., 2014; Korsak et al., 2015

Dobson et al., 2011; Nalbantoglu et al., 2014

Dobson et al., 2011

Nalbantoglu et al., 2014; Garofalo et al., 2015

Nalbantoglu et al., 2014; Garofalo et al., 2015

Nalbantoglu et al., 2014; Garofalo et al., 2015

Nalbantoglu et al., 2014; Garofalo et al., 2015

Garofalo et al., 2015

Nalbantoglu et al., 2014

Angulo et al., 1993; Pintado et al., 1996; Garrote et al., 2001; Simova et al., 2002; Witthuhn et al., 2004, 2005; Yüksekdağ et al., 2004; Mainville et al., 2006; Chen et al., 2008; Garofalo et al., 2015; Zanirati et al., 2015

Yüksekdağ et al., 2004; Mainville et al., 2006; Korsak et al., 2015

Garrote et al., 2001

Nalbantoglu et al., 2014

Angulo et al., 1993

Simova et al., 2002; Yüksekdağ et al., 2004; Mainville et al., 2006; Garofalo et al., 2015

Yüksekdağ et al., 2004

Angulo et al., 1993

Witthuhn et al., 2004; Mainville et al., 2006

Witthuhn et al., 2005; Mainville et al., 2006

Simova et al., 2002; Chen et al., 2008; Nalbantoglu et al., 2014; Korsak et al., 2015; Zanirati et al., 2015

Mainville et al., 2006

Nalbantoglu et al., 2014 
TABLE 1 | Continued

\section{Microbial species}

\section{Acetobacter}

Acetobacter spp.

Acetobacter sicerae

Acetobacter orientalis, Acetobacter

lovaniensis

\section{Bifidobacterium}

\section{Bifidobacterium spp.}

Bifidobacterium breve, B. choerinum,

B. longum, B. pseudolongum

Yeast and fungal species

Zygosaccharomyces spp.

Candida kefyr

Candida lipolytica

Saccharomyces cerevisiae

\section{Candida holmii}

\section{Torulaspora delbrueckii}

Saccharomyces unisporus

\section{Candida friedrichii}

Kluyveromyces lactis

Pichia fermentans

Issatchenkia orientalis

Kluyveromyces marxianus

Saccharomyces turicensis

Dekkera anomala

Kazachstania exigua

Naumovozyma spp.

Cryptococcus humicolus,

Geotricum candidum

Kazachstania servazzii, Ka. solicola,

Ka. aerobia, Saccharomyces

cariocanus

Kluyveromyces marxianus var. lactis, Candida inconspicua, C. maris

Saccharomyces humaticus, Candida sake, Yarrowia lipolytica, Dipodascus capitatus, Trichosporon coremiiforme Ganoderma lucidum, Dioszegia hungarica, Heterbasidion annosum, Peziza campestris, Cyberlindnera jadinii, Malassezia pachydermatis, Teratosphaeria knoxdaviesii, Cryptococcus sp. Vega 039, Microdochium nivale, Wallemia sebi, Zygosaccharomyces lentus, Eurotium amsteldami, Dekkera bruxellensis, Kazachstania barnettii, Naumovozyma castelli, Davidiella tassiana, Penicillium sp. Vega 347

\section{Reference}

\author{
Angulo et al., 1993; Garrote et al., 2001; Marsh et al., 2013; Garofalo et al., 2015 \\ Li et al., 2014 \\ Korsak et al., 2015
}

Marsh et al., 2013

Dobson et al., 2011

Witthuhn et al., 2004, 2005

Angulo et al., 1993; Marquina et al., 2002; Witthuhn et al., 2004

Witthuhn et al., 2004

Angulo et al., 1993; Marquina et al., 2002; Simova et al., 2002; Witthuhn et al., 2004; Latorre-García et al., 2007; Marsh et al., 2013; Vardjan et al., 2013; Diosma et al., 2014; Garofalo et al., 2015

Angulo et al., 1993; Witthuhn et al., 2004; Latorre-García et al., 2007

Angulo et al., 1993; Vardjan et al., 2013

Angulo et al., 1993; Pintado et al., 1996; Marquina et al., 2002; Latorre-García et al., 2007; Wang et al., 2008; Marsh et al., 2013; Vardjan et al., 2013; Diosma et al., 2014; Garofalo et al., 2015

Angulo et al., 1993

Angulo et al., 1993; Marquina et al., 2002; Latorre-García et al., 2007

Angulo et al., 1993; Wang et al., 2008; Marsh et al., 2013

Latorre-García et al., 2007; Marsh et al., 2013; Diosma et al., 2014

Marquina et al., 2002; Wang et al., 2008; Marsh et al., 2013; Vardjan et al., 2013; Diosma et al., 2014; Korsak et al., 2015

Wang et al., 2008; Garofalo et al., 2015

Marsh et al., 2013; Garofalo et al., 2015

Vardjan et al., 2013; Garofalo et al., 2015; Korsak et al., 2015

Korsak et al., 2015

Witthuhn et al., 2005

Garofalo et al., 2015

Simova et al., 2002

Latorre-García et al., 2007

Marsh et al., 2013

\section{Yeast Populations}

In addition to the large and variable bacterial population in kefir grains, there is an abundant yeast population that exists in a symbiotic relationship with the bacteria (Simova et al., 2002; Witthuhn et al., 2004; Marsh et al., 2013). Three genera of yeasts are commonly isolated from kefir grains or milk, and typically make up the majority of the total yeast population; Saccharomyces, Kluyveromyces, and Candida (Angulo et al., 1993; Marquina et al., 2002; Simova et al., 2002; Diosma et al., 2014). 


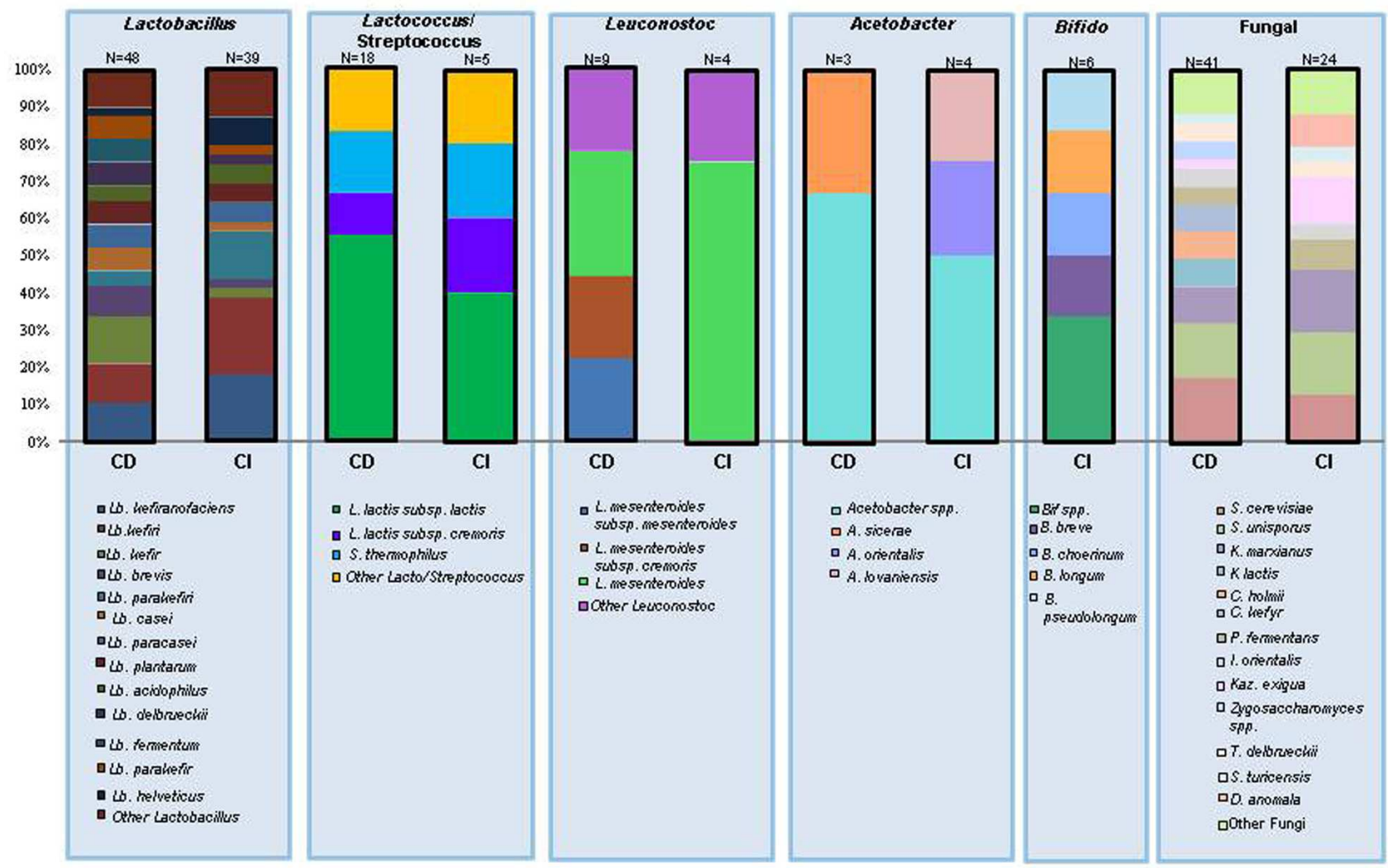

FIGURE 3 | The number of times an individual species has been identified in kefir expressed as a percentage of the total number of species in the same genera. $\mathrm{CD}$, culture dependent identification; $\mathrm{Cl}$, culture independent identification; $N$ values represent the total number of times a species within the genus has been identified.

Many different species of Saccharomyces have been isolated from kefir, however, S. cerevisiae and S. unisporus are the most common and present in many varieties (Angulo et al., 1993; Marquina et al., 2002; Latorre-García et al., 2007; Diosma et al., 2014). Kluyveromyces make up the majority or entirety of the lactose utilizing yeast population, with $K$. marxianus and $K$. lactis being the two most common species (Simova et al., 2002; LatorreGarcía et al., 2007; Diosma et al., 2014). The Candida population is made up of a wide range of species with $C$. holmii and C. kefyr being the most prevalent (Angulo et al., 1993; Marquina et al., 2002). Outside of these three genera, only Pichia has been identified with any regularity and in each case the species was identified as Pichia fermentans (Angulo et al., 1993; Wang et al., 2008). As fermentation progresses the proportions of some yeast species change with non-lactose fermenting yeasts, such as Saccharomyces, decreasing, whereas lactose utilizing $K$. marxianus and $K$. lactis show a similar distribution between grain and kefir (Simova et al., 2002).

Unlike the bacterial population in kefir grain, the yeast component of the grain fluctuates considerably between grains when analyzed using culture independent techniques. Despite this, a small number of yeasts such as Kazachstania, Kluyveromyces, and Naumovozyma tend to be the dominant genera present in both the grain and fermented milk (Zhou et al.,
2009; Marsh et al., 2013; Vardjan et al., 2013; Garofalo et al., 2015; Korsak et al., 2015). Of these main genera, only Naumovozyma has not been isolated in culture based studies. Kazachstania unispora, the species of Kazachstania present is also known as Saccharomyces unisporus (Marsh et al., 2013). Sequencing based approaches have also identified over a dozen yeast species that had not previously been associated with kefir, such as Dekkera anomala, Issatchenkia orientalis, and Pichia fermentans, and have even shown that, in some grains, the yeast population is dominated by a mix of these other species (Marsh et al., 2013; Garofalo et al., 2015). Table 1 contains a complete list of yeast species found in culture dependent and culture independent studies.

\section{Culture Dependent vs. Culture Independent Methods}

As expected, sequencing based methods often identify organisms that are not readily isolated by traditional culture based methods. This may be due to the presence of these organisms in extremely low numbers, or some of these organisms may be unable to grow on traditional media due to the complex symbiotic relationships present in kefir. Indeed, this may account for why certain Lactobacillus species have only been identified in sequencing 
based studies (Dobson et al., 2011). For example L. kefiranofaciens has not consistently been isolated in culture based methods but is regularly identified as a major part of the Lactobacillus population present in kefir when culture independent methods are used which may be due to the more strict anaerobic nature of this species when compared to other Lactobacillus species (Wang et al., 2012). While sequencing based methods have proven to be very valuable for identifying difficult to culture organisms, high throughput sequencing of $16 \mathrm{~S}$ amplicons are limited with respect to their ability to consistently identify organisms at the species level (Marsh et al., 2013). Additionally, with metagenomic analyses there is the possibility that population dynamics may be skewed if there are dead cells present. While large numbers of dead cells from one species may indicate the importance of that species to kefir, the detection of these dead cells can still be problematic at later times during fermentation as they would not be actively involved in the community at these time points. Culture based methods remain essential as they allow organisms to be phenotypically tested. Regardless, the advent of sequence based technologies has increased the knowledge of which organisms are present in kefir grains and fermented milk and will allow for the development of new strategies to facilitate the isolation of organisms previously overlooked.

\section{CHOLESTEROL METABOLISM AND ACE INHIBITION}

Due to the highly complex microbiota of kefir, there is a multitude of organisms and metabolic products present in the fermented milk. This combination of live microbial organisms and metabolites contributes to a wide range of effects attributed to kefir many of which are health benefits. Cardiovascular disease (CVD) is one of the leading causes of death in the western world, with high levels of serum cholesterol being a major risk factor for the disease. Diet can play a major role in the management of serum cholesterol levels and thus, ones risk of contracting CVD (WHO, 1982). It has been shown that milk and especially fermented milks are able to reduce serum cholesterol levels in animal trials (Beena and Prasad, 1997; Sibel Akalin et al., 1997). Kefir grains are capable of reducing the cholesterol levels of milk through the fermentation process and have been shown to reduce the levels of cholesterol present by between 41 and $84 \%$ after $24 \mathrm{~h}$ fermentation and a further $48 \mathrm{~h}$ of storage (Vujičić, 1992). While cholesterol reduction varied from one grain to another, these differences did not reflect the country of origin of the grain; Yugoslavian grains had both the highest and lowest levels of cholesterol reduction. Single kefir isolates have also been shown to assimilate cholesterol, with $K$. marxianus being one of the more effective. When K. marxianus strains K1 and M3 were inoculated in broth supplemented with cholesterol for $20 \mathrm{~h}$, cholesterol levels decreased 70-99\% (Liu et al., 2012). These same strains of $K$. marxianus showed significant levels of bile salt hydrolase (BSH) activity which were proportional to the rate of cholesterol lowering (Liu et al., 2012). BSH deconjugates bile acids and, as deconjugated bile salts is less soluble and less efficiently reabsorbed from the intestinal lumen, this leads to increased bile salt excretion in the faces (Zhuang et al., 2012). BSH deconjugation contributes to cholesterol lowering abilities of kefir as cholesterol is utilized in bile acid synthesis.

Cholesterol lowering properties of kefir have been validated in animal models. In a study using male golden Syrian hamsters fed cholesterol free or cholesterol enriched diet, both milk kefir and soyamilk kefir reduced serum triacylglycerol and total cholesterol while improving the atherogenic index (i.e., ratio of non-HDL-cholesterol to HDL-cholesterol). The cholesterol lowering effect was independent of whether the hamsters were fed the cholesterol free or cholesterol enriched diet (Liu et al., 2006a) indicating that kefir feeding altered endogenous cholesterol metabolism. Concentrations of cholesterol in the liver were also observed to decrease in both milk kefir and soyamilk kefir fed hamsters, and the secretion levels of fecal bile acid and cholesterol significantly increased for both groups. The increase in fecal bile acid is likely a result of the deconjugation of bile acid by microbes present in the kefir, while the higher levels of cholesterol secretion were likely due to the inhibition of cholesterol absorption in the small intestine due to the binding and assimilation of cholesterol by these same microbes (Xiao et al., 2003).

Lactobacillus plantarum MA2 isolated from kefir has also shown hypocholesterolemic activity in male Sprague-Dawley (SD) rats fed a high cholesterol diet. Rats fed a diet supplemented with this organism had significantly lower total serum cholesterol, LDL-cholesterol, triglycerides, liver cholesterol and triglycerides in conjunction with increased fecal cholesterol secretion (Wang et al., 2009). A similar study that used a high cholesterol diet supplemented with L. plantarum strains Lp09 and Lp45 in SD rats found that these strains had the same effect (Huang et al., 2013a). Huang et al. (2013b) also found that L. plantarum Lp27 was able to decrease serum total cholesterol, LDL-cholesterol, and triglycerides in hypercholesterolemic SD rats that consumed a diet supplemented with Lp27. A proposed mechanism for decreased serum cholesterol is the inhibition of cholesterol absorption. The Niemann-Pick C1-like 1 (NPC1L1) gene, which plays a critical role in the absoption of cholesterol (Altmann et al., 2004), is down-regulated in rats fed Lp27 and in in vitro tests with Caco-2 cells (Huang et al., 2013b). Zheng et al. (2013) found that L. acidophilus LA15, L. plantarum B23, and L. kefiri D17 were all able to lower serum total cholesterol, LDL, and triglyceride levels in SD rats fed a high cholesterol diet. The three strains also increased fecal cholesterol and bile acid secretion (Zheng et al., 2013). K. marxianus YIT 8292 was also shown to decrease plasma and liver cholesterol levels in addition to increasing fecal sterol and bile acid excretion and the concentration of short chain fatty acids in the cecum (Yoshida et al., 2005), indicating that both bacteria and yeast can contribute to this characteristic. This effect was shown to be specific to $\alpha$-mannan and $\beta$-glucan present in the cell wall of $K$. marxianus (Yoshida et al., 2005). In addition to individual microbes in kefir having an ability to reduce cholesterol, kefiran has also been shown to improve cholesterol and blood pressure levels. 
In a study using spontaneously hypertensive and stroke prone (SHRSP/Hos) rats fed a high fat diet, kefiran supplementation reduced serum total cholesterol, serum LDL-cholesterol, serum triglycerides, liver cholesterol, and liver triglycerides (Maeda et al., 2004b), however, the concentrations used for kefiran supplementation were not discussed. Decreases in the blood pressure and angiotensin converting enzyme (ACE) activity were also observed. ACE inhibitory action has been attributed to commercial kefir made from caprine milk when tested in vitro, with the mode of action being attributed to two small peptides released from casein during the fermentation process (Quiros et al., 2005).

In contrast to these studies, St-Onge et al. (2002) found that when mildly hypercholesterolemic men consumed kefir as part of their diet for 4 weeks there was no significant change to total serum cholesterol, LDL-cholesterol, HDLcholesterol, or triglyceride concentrations. They did note an increase in fecal bacterial counts and short chain fatty acid levels, including propionic acid. Additionally, a study examining Wistar rats fed a standard diet supplemented with kefir for 22 days found no significant differences in serum cholesterol when compared to rats on a control diet (Urdaneta et al., 2007). While these two studies seem to conflict with other findings, this may be in large part due to the fact that different kefir grains were used for each of these studies. Additionally, the aforementioned Liu et al. (2006a) study had a timeline of 8 weeks, while St-Onge et al. (2002) and Urdaneta et al. (2007) had timelines of 4 weeks and 22 days, respectively. It may be significant that, in the study of hypercholesterolemic men, an increase in fecal propionic acid was noted. Propionic acid has been shown to inhibit acetate incorporation in to triacylglycerol and plasma cholesterol (Wolever et al., 1995). Thus, a hypocholesterolemic effect may have been observed had the study continued for a longer time period.

\section{EFFECTS ON THE HOST GUT AND GUT MICROBIOME}

\section{Pathogen Exclusion}

One of the main ways through which probiotic-containing food products can exert beneficial effects is altering the gut microbiota. This can be done either through the introduction of new species or strains in to the gastrointestinal tract, or by promoting the growth of beneficial microbes which are already present. Some examples are presented here. In multiple studies, consumption of kefir or kefiran in an animal model has been associated with an increase in microbes thought of as beneficial, such as Lactobacillus and Bifidobacterium, while simultaneously decreasing harmful microbial species such as Clostridium perfringens (Liu et al., 2006b; Hamet et al., 2016). Kefir consumption was also able to reduce the severity of Giardia intestinalis infection in C57BL/6 mice, with the reported mechanism being through modulation of the immune system (Correa Franco et al., 2013). Furthermore, specific strains of Lactobacillus isolated from kefir have been shown to adhere to Caco-2 cells and inhibit the adherence of Salmonella typhimurium and Escherichia coli O157:H7 (Santos et al., 2003; Hugo et al., 2008; Huang et al., 2013a). The ability of these Lactobacillus species to bind to Caco-2 cells illustrates a likely mechanism for the increase in Lactobacillus species observed in the fecal microbiota of rats fed kefir (Liu et al., 2006b; Carasi et al., 2015). In an in vivo study where $\mathrm{BALB} / \mathrm{c}$ mice were intragastrically challenged with $E$. coli O157:H7, mice receiving L. kefiranofaciens $\mathrm{M} 1$ prior to $E$. coli challenge showed reduced symptoms of infection, including intestinal and renal damage, bacterial translocation, and Shiga toxin penetration as well as increased EHEC-specific mucosal IgA responses (Chen et al., 2013)

Other in vitro work has also shown that lactobacilli isolated from kefir have the ability to protect Vero cells from type II Shiga toxin produced by E. coli O157:H7, leading to lower levels of cell death (Kakisu et al., 2013). Similar effects were apparent in another study where they observed that kefir fermented milk inhibited the ability of Bacillus cereus extracellular factors to cause damage to Caco-2 cells (Kakisu et al., 2007).

As well as regulating microbial composition, kefir can alter the activity of the microbiota. Certain Bifidobacterium strains have been shown to exhibit increases in growth rate when cultured in kefir and changes in gene expression have also been observed (Serafini et al., 2014). These changes in gene expression resulted in increased expression levels of multiple genes associated with pil3, a sortase dependent pilus that has been shown to be extremely important for interaction with the host endothelial cells and is especially important for adherence and modulation of the host inflammatory response (Turroni et al., 2013; Serafini et al., 2014). While this specific example shows the potential positive effects kefir can have on existing organisms within the gut microbiota, it is still unclear as to how this translates to the complex population of the whole microbiome.

\section{Antibacterial and Antifungal Properties}

Kefir, and kefir associated strains, has shown a multitude of antibacterial and antifungal activities (Table 2). Kefir fermented milk has been tested in disk diffusion experiments against a wide range of pathogenic bacterial and fungal species and found to have antimicrobial activity equal to ampicillin, azithromycin, ceftriaxone, amoxicillin, and ketoconazole against many of these species (Cevikbas et al., 1994; Yüksekdağ et al., 2004; Rodrigues et al., 2005; Huseini et al., 2012).

In addition to the antimicrobial effects of kefir fermented milk as a whole, there are also specific microbes which exert antimicrobial properties on their own. For instance, L. plantarum ST8KF produces the bacteriocin ST8KF which exhibits antimicrobial action against Enterococcus mundtii and Listeria innocua (Powell et al., 2007). Other kefir-derived Lactobacillus species such as L. acidophilus and L. kefiranofaciens, as well as some $S$. thermophilus strains have shown antimicrobial activity against a whole range of pathogenic organisms including E. coli, L. monocytogenes, S. aureus, S. typhimurium, S. enteritidis, $S$. flexneri, $P$. aeruginosa, and $Y$. enterocolitica when tested using an agar spot test (Santos et al., 2003; 
TABLE 2 | List of pathogenic organisms that kefir or kefir-associated organisms have demonstrated antimicrobial effects against.

\begin{tabular}{|c|c|}
\hline Microbial species & Reference \\
\hline \multicolumn{2}{|l|}{ Bacteria } \\
\hline Staphylococcus aureus & $\begin{array}{l}\text { Cevikbas et al., 1994; Ryan et al., 1996; Yüksekdağ et al., 2004; Rodrigues } \\
\text { et al., 2005; Miao et al., 2014; Leite et al., 2015; Zanirati et al., } 2015\end{array}$ \\
\hline Pseudomonas aeruginosa & $\begin{array}{l}\text { Cevikbas et al., 1994; Ryan et al., 1996; Yüksekdağ et al., 2004; Rodrigues } \\
\text { et al., 2005; Huseini et al., 2012; Zanirati et al., } 2015\end{array}$ \\
\hline Salmonella typhimurium & $\begin{array}{l}\text { Santos et al., 2003; Rodrigues et al., 2005; Golowczyc et al., 2008; Zanirati } \\
\text { et al., } 2015\end{array}$ \\
\hline Escherichia coli & $\begin{array}{l}\text { Ryan et al., 1996; Santos et al., 2003; Yüksekdağ et al., 2004; Rodrigues et al., } \\
\text { 2005; Golowczyc et al., 2008; Leite et al., 2015; Zanirati et al., } 2015\end{array}$ \\
\hline Salmonella enteritidis & Santos et al., 2003; Miao et al., 2014 \\
\hline Listeria monocytogenes & $\begin{array}{l}\text { Ryan et al., 1996; Santos et al., 2003; Rodrigues et al., 2005; Likotrafiti et al., } \\
\text { 2015; Leite et al., 2015; Zanirati et al., } 2015\end{array}$ \\
\hline Bacillus subtilis & Cevikbas et al., 1994; Ryan et al., 1996 \\
\hline Salmonella enterica & Golowczyc et al., 2008; Miao et al., 2014; Leite et al., 2015 \\
\hline Enterococcus faecalis & Ryan et al., 1996; Zanirati et al., 2015 \\
\hline Shigella flexneri & Santos et al., 2003 \\
\hline Clostridium difficile & Rea et al., 2007 \\
\hline Klebsiella pneumonia, Proteus vulgaris & Cevikbas et al., 1994 \\
\hline Streptococcus pyogenes, Staphylococcus salivarius & Rodrigues et al., 2005 \\
\hline $\begin{array}{l}\text { Bacillus cereus, Clostridium sporogenes, } \\
\text { C. tyrobutyricum, Enterococcus faecium, } \\
\text { Listeria innocua, Salmonella typhi }\end{array}$ & Ryan et al., 1996 \\
\hline Salmonella gallinarum, Shigella sonnei & Golowczyc et al., 2008 \\
\hline Bacillus thuringiensis, Shigella dysenteriae & Miao et al., 2014 \\
\hline \multicolumn{2}{|l|}{ Fungus } \\
\hline Candida albicans & Rodrigues et al., 2005 \\
\hline Yersinia entocolitica & Santos et al., 2003 \\
\hline $\begin{array}{l}\text { Aspergillus flavus, A. niger, Rhizopus nigricans, Penicillium } \\
\text { glaucum }\end{array}$ & Miao et al., 2014 \\
\hline $\begin{array}{l}\text { Staphylococcus epidermidis, Candida stellatoidea, } \\
\text { C. tropicalis, C. krusei, Saccharomyces cerevisiae, } \\
\text { Rhodotorula glutinis, Torulopsis glabrata }\end{array}$ & Cevikbas et al., 1994 \\
\hline
\end{tabular}

Yüksekdağ et al., 2004; Golowczyc et al., 2008). Other kefir lactobacilli have also shown antimicrobial activity in in vitro tests against $S$. typhimurium, and E. coli that have already adhered to Caco-2 cells (Golowczyc et al., 2008). Lacticin 3147 is produced by a strain of L. lactis isolated from kefir and has an extremely broad range of antimicrobial activity, affecting B. cereus, B. subtilis, C. sporogenes, C. tyrobutyricum, Enterococcus faecium, E. faecalis, L. innocua, L. monocytogenes, S. aureus, and C. difficile (Ryan et al., 1996; Rea et al., 2007). Another bacteriocin of kefir origin is F1, which is produced by the Lactobacillus paracasei subsp. tolerans strain FX-6 source from a Tibetan kefir grain. F1 has been shown to inhibit a wide range of bacterial and fungal species including S. aureus, Shigella dysenteriae, and Aspergillus niger (Miao et al., 2014). L. kefiri B6 isolated from kefir was also capable of inhibiting and inactivating L. monocytogenes when in the presence of galactooligosaccharide in vitro, however, this effect was not observed with $E$. coli and, in this case, further investigation of the mechanism of this inactivation is needed (Likotrafiti et al., 2015). Similarly, Leite et al. (2015) isolated multiple strains of L. lactis and Lb. paracasei from kefir capable of producing bacteriocin-like substances that were inhibitory to E. coli, S. enterica, S. aureus, and L. monocytogenes, however, more work is needed in order to better characterize these substances and determine the range of their antimicrobial activity as well as their novelty. In a study examining $\mathrm{LAB}$ isolated from Brazilian kefir grains, L. kefiranofaciens $8 \mathrm{U}$ showed the ability to inhibit multiple pathogens including $P$. aeruginosa, L. monocytogenes, and E. faecalis in vitro, but again more work is needed in order to determine the mechanism behind this inhibition (Zanirati et al., 2015).

\section{ANTITUMOR EFFECTS}

Kefir also has significant antitumor activity against multiple cancer cell types. L. kefiri was shown to increase apoptosis of multiple drug resistant human myeloid leukemia cells in vitro through the activation of caspase 3 in a dose dependent manner (Ghoneum and Gimzewski, 2014). The cell free fraction of kefir has shown antitumor activity in vitro when it was observed to have a dose dependent anti-proliferative effect on the gastric cancer cell line SGC7901 (Gao et al., 
2013). This study further demonstrated that cell free kefir was able to induce apoptosis in SGC7901 cells through up regulation of the bax gene, and apoptosis promoter and antioncogene, and down regulation of the $b c l-2$ gene, which is an apoptosis inhibitor and known oncogene (Sorenson, 2004). In addition to the promotion of cell death in cancerous cells, antimutagenic effects have been demonstrated in studies with known carcinogens such as methylmethanosulphate, methy-lazoxymethanol, sodium azide, aflatoxin B1, and 2aminoanthracene as indicated by the Ames test (Guzel-Seydim et al., 2006).

In mouse models of fusiform cell sarcomas, mice receiving intraperitoneal kefir had reduced tumor size, with some tumors completely disappearing over a 20 days treatment period (Cevikbas et al., 1994). While this is impressive, it has yet to be determined if these findings can be replicated in the case of oral consumption. A separate study utilizing a murine breast cancer model showed that kefir feeding prior to challenge with the tumor resulted in decreased size and increased apoptosis of the tumor, and that the levels of IgA + cells and CD4 $+\mathrm{T}$ cells were also increased (de Moreno de LeBlanc et al., 2007). Mice with breast cancer tumors fed kefir also showed increased serum levels of Il-10 and IL-4 (de Moreno de LeBlanc et al., 2006). These studies both showed increases in immune cell populations and recruitment, pointing to a possible mechanism for the reduction of tumor size. These findings are consistent with other studies that have shown that kefir is able to modulate the immune system in the gut and show that the immunomodulatory abilities of kefir may not be limited to the gastrointestinal tract (Thoreux and Schmucker, 2001; Vinderola et al., 2005; Correa Franco et al., 2013).

\section{WOUND HEALING}

The antimicrobial properties of kefir may lead to its use for nontraditional applications. Indeed, when rats bearing open wounds inoculated with $S$. aureus were treated with a gel made from kefir grains, it was found that the wounds healed at a much faster rate than was observed in control rats that received no treatment or rats that received a traditional treatment of $5 \mathrm{mg} / \mathrm{kg}$ neomycinclostebol emulsion (Rodrigues et al., 2005). Gels made from kefir and kefir grains were found to be more effective at reducing wound size in $P$. aeruginosa contaminated third degree burns than a traditional silver sulfadiazine treatment in a rat model of burn wounds (Huseini et al., 2012; Rahimzadeh et al., 2014). Furthermore, a study using a rabbit model for contaminated open wound also found that gel made from kefir grain resulted in quicker healing times and quicker clearing of infection (Atalan et al., 2003).

These decreased healing times are likely due to multiple factors. One such factor is the ability of kefir to inhibit the growth of bacterial and fungal cells, thus leading to a cleaner wound, as shown to be the case in some studies (Atalan et al., 2003; Huseini et al., 2012). Another possible factor is the ability to modulate the immune system and recruit immune cells to help with the healing process.

\section{IMMUNOMODULATORY EFFECTS}

One of the major ways probiotic products such as kefir are able to produce health benefits is through the modulation of the gastrointestinal immune system. When young rats inoculated intra-duodenally with cholera toxin (CT) were fed kefir, the levels of anti-CT IgA in the serum increased as did the secretion levels of anti-CT IgA in the Peyer's Patches, the mesenteric lymph nodes, the spleen, and the intestinal lamina propria compared to CT alone (Thoreux and Schmucker, 2001). This same effect, however, was not observed in older mice that underwent the same treatment, suggesting that whatever mechanism is responsible for the observed change in the young rats is either no longer present in the senescent mice or requires a much larger dosage of kefir in order to activate it. Additional studies in to the mechanism as well as investigations with middle aged mice are needed to provide further insight in to this phenomenon. In an infection of C57BL/6 mice with G. intestinalis, kefir consumption reduced intensity of infection by mitigating the ability of $G$. intestinalis to suppress the mounting of an inflammatory response. This impact was mediated through increases in the levels of TNF- $\alpha$ and IFN- $\gamma$ expression and through higher levels of IgA positive and RcFce positive cells (Correa Franco et al., 2013). There have also been studies showing increases in IgA and IgG+ cells in the small intestine of rats that were fed both regular and pasteurized kefir, as well as increases in the levels of IL4, IL-10, IL-6, and IL-2 positive cells in the lamina propria of these same rats. Increases were also seen in anti-inflammatory cytokines such as IL-10, IL-4, and IL-6, all of which promote a Th2 response (Vinderola et al., 2005). Interestingly, increases in IFN- $\gamma$, TNF $\alpha$, and IL-12 (all of which are pro-inflammatory and promote a Th1 response) were observed only in rats fed pasteurized kefir. The increase in pro-inflammatory cytokines in the pasteurized kefir groups was likely due to the reduced cell wall integrity of heat killed cells exposing more inflammatory microbial products. The fact that pasteurized kefir was able to elicit an effect shows that the mechanisms behind this immune modulation are not entirely dependent on live cells, and may be due to metabolites present in the kefir (Iraporda et al., 2014). However, it should be noted that in this study live cells had a generally more substantial impact as live kefir was able to confer a similar effect at $1 / 10$ the concentration and without eliciting a pro-inflammatory immune response (Vinderola et al., 2005).

When fed to mice over 2-7 days, solid fractions of kefir that contained live bacteria have been shown to increase the levels of IFN- $\gamma$, TNF- $\alpha$, and IL- 6 in peritoneal macrophages as well as to increase the levels of IL-1 $\alpha$, IL-10, and IL6 in adherent cells isolated from the Peyer's patch of mice (Vinderola et al., 2006b). IFN- $\gamma$ and TNF- $\alpha$ increased early in feeding, however, they quickly decreased back to control levels by day 7 along with IL- $1 \alpha$ while IL- 6 and IL-10 levels remained high through the 7 days feeding period (Vinderola et al., 2006b). In vitro experiments with lactobacilli isolated from kefir have shown that they induce higher secretion levels of IL-1 $\beta$, IL-6, TNF- $\alpha$, IL-10, IL-8, and IL-12 in peripheral blood mononuclear cells and are able to decrease the ccl20 
response in Caco-2 cells to TLR agonists such as bacterial flagella, with largely different effects being observed for different strains of lactobacilli tested (Carasi et al., 2015). In general, strains of L. kefiri that induced lower TNF- $\alpha /$ IL-10 and higher IL-10/IL-12 ratios showed a much greater decrease in the proinflammatory response of $\mathrm{ccl} 20$ to stimulation with bacterial flagella, indicating the importance of IL-10 in promoting a Th2 response while simultaneously inhibiting the pro-inflammatory Th1 response. Mice that were fed L. kefiri for a period of 21 days showed altered gene expression profiles in the ileum, colon, Peyer's Patches, and mesenteric lymph nodes, with proinflammatory cytokines such as IFN $-\gamma$ and IL-23 being down regulated and IL-10 being up regulated (Carasi et al., 2015). This further indicates that lactobacilli isolated from kefir have the ability to supress the production of pro-inflammatory cytokines while promoting anti-inflammatory cytokine production. $L$. kefiranofaciens co-incubation with mouse macrophage cells decreased the levels of pro-inflammatory cytokines IL-1 $\beta$, and IL-12 while simultaneously increasing the level of the antiinflammatory cytokine IL-10, which acts to specifically inhibit the production of IL-12 and IL-1 $\beta$ (Hong et al., 2009). Additionally, L. kefiranofaciens was able to ameliorate colitis in a DSS induced mouse model and enhance Th1 responses to TLR agonists in germ free mice by increasing the production of IFN- $\gamma$ and IL-12 upon stimulation (Chen and Chen, 2013). Further investigation into the mechanisms of protection against colitis showed that L. kefiranofaciens M1 decreased the production of pro-inflammatory cytokines IL- $1 \beta$ and TNF- $\alpha$, while increasing the production of IL-10 in vivo (Chen et al., 2012). This effect was also TLR-2 dependent as L. kefiranofaciens M1 was unable to improve DSS colitis in TLR-2 knockout mice (Chen et al., 2012).

The cell free fraction of kefir is also capable of modulating the immune system, and has been shown to modulate innate immune responses in vitro by lowering the activation of Caco2-ccl20:luc cells that had been stimulated by Salmonella flagellar protein FliC, IL-1 $\beta$, or TNF- $\alpha$ (Iraporda et al., 2014). One of the likely mechanisms was revealed when it was found that a $100 \mathrm{mM}$ lactic acid solution at $\mathrm{pH} 7$ was able to elicit a comparable level of immune modulation in FliC stimulated cells when preincubated with the solution (Iraporda et al., 2014). The lactic acid solution was also found to lower the level of NFK-B activation in Caco-2 cells stimulated with FliC and was even able to down regulate the expression of proinflammatory cytokines ccl20, IL-8, CXCL 2, and CXCL 10 without affecting genes involved in the normal function of enterocytes (Iraporda et al., 2014). These results indicate just how important the metabolites produced during fermentation are to the ability of kefir to elicit beneficial responses or effects in the host.

In general studies using whole kefir, kefir fractions, or organisms isolated from kefir found that whether tested in vitro or in vivo, the result was a shift from a Th1 immune response to a Th2 response as well as increases in the levels of IgA present (Thoreux and Schmucker, 2001; Vinderola et al., 2005, 2006b; Hong et al., 2009; Carasi et al., 2015). The only study which seems to show a consistently increased Th1 response was conducted with germ free mice, while all other studies used conventional mice or rats (Chen and Chen, 2013). This may account for the difference in findings as it is quite possible that the observations from the germ free mice had more to do with the introduction of a bacterial population to the gut than it did with the specific bacterial species that comprised that population. The fact that most studies also observed increases in some proinflammatory cytokines such as TNF- $\alpha$, IFN- $\gamma$, or IL-12 may be explained by an initial reaction of the immune system to common TLR agonists present, which was ultimately supressed following further interaction with the immune cells of the GI tract.

\section{ANTI-ALLERGENIC EFFECTS}

Allergic diseases have been on the rise in the developed world for decades, leading to higher incidences of conditions such as asthma and food allergy (Yazdanbakhsh et al., 2002). Many allergies, especially those related to food, are developed early in life, with the majority of food allergies developing within the first 2 years of life (Wood, 2003). Although most food allergies developed early in life do not persist, some can become lifelong conditions (Wood, 2003). Recent work has shown that an increasingly important factor in determining if a child develops allergic disease, be it food allergy or asthma, is the level of complexity and the specific organisms present in the gut microbiota (Kirjavainen et al., 2002; Sjogren et al., 2009; Azad et al., 2013; West, 2014). Higher levels of Bifidobacterium and group 1 lactobacilli (obligate heterofermentative lactobacilli such as L. acidophilus, L. delbrueckii, and L. helveticus) in the gut of infants have been associated with a lower incidence of allergic disease later in life (Sjogren et al., 2009), and both kefir and kefiran have been observed to exert these effects on the gut microbiota in animal trials (Liu et al., 2006b; Hamet et al., 2016). Supplementation with Bifidobacterium has been shown to influence the intestinal microbiota of weaning infants by reducing levels of Bacteroides and has been associated with lower incidence of food allergy (Kirjavainen et al., 2002). Studies with antibiotics in the early life period have also highlighted the importance of appropriate microbial stimulation of the immune system for protection against asthma development (Russell et al., 2012).

One of the main mechanisms behind food allergy is an imbalance in the Th1/Th2 cell ratio, leading to a heightened IgE response (Tanabe, 2008). Studies of in vitro reactions of human monocytes with a probiotic made up of multiple LAB showed that exposure to these LAB resulted in a much higher IFN- $\gamma / \mathrm{IL}-$ 4 ratio, similar to what would be seen during a Th1 response (Tsai et al., 2012). In addition to the in vitro studies carried out, Tsai et al. (2012) found that both total IgE and OVA-specific IgE were significantly lower in mice that had been sensitized to OVA (ovalbumin) and then fed a LAB mixture than in control mice which had also been sensitized to OVA but did not receive any LAB mixture. Studies such as this indicate that kefir may help relieve some allergy symptoms. 
In a study utilizing an ovalbumin sensitization mouse asthma model, it was found that mice receiving intra-gastric kefir showed lower levels of airway hyper-responsiveness (AHR) than control mice, and, impressively, had lower levels of AHR than the positive control group receiving an anti-asthma drug (Lee et al., 2007). This same study found that mice receiving kefir exhibited significantly lower levels of eosinophil infiltration in the lung tissue as well as in the brochoalveolar lavage fluid (BALF). These mice also showed lower levels of IgE, IL-4, and IL-13 in the BALF, all of which are associated with the Th2 response which is responsible for allergic reaction (Lee et al., 2007). It has also been found that oral feeding of kefir in OVA sensitized mice resulted in significantly lower levels of anti-OVA serum IgE and IgG1 antibodies than those found in mice given water or unfermented milk (Liu et al., 2006b). Studies examining the in vitro effect of heat-killed lactobacilli isolated from kefir on mouse peritoneal macrophages showed that even after being heat-inactivated, the lactobacilli were able to induce the expression of Th1 cytokines such as IFN- $\gamma$, TNF- $\alpha$, IL-12, and IL-1 $\beta$ (Hong et al., 2010). These same heat-inactivated lactobacilli also reduced the levels of anti-OVA IgE in the serum when fed orally to OVA sensitized mice, while increasing the expression of IL-12 and decreasing the expression of IL-5 in splenocytes. An increase in the levels of regulatory $\mathrm{T}$-cells was also detected in these mice (Hong et al., 2010). In a study of OVA sensitized mice fed with heat-inactivated strain M1 of L. kefiranofaciens, the inactivated M1 was able to decrease levels of pro-inflammatory and Th2 cytokines such as IL-4, IL-6, IL13, and ccl20 in both the splenocytes and BALF of the mice while decreasing OVA-specific IgE and the Th17 associated cytokine IL-17, both of which are strongly associated with an asthmatic response. The M1 treatment was also able to increase the levels of regulatory T cells present (Hong et al., 2011).

While all of these studies reveal a consistent pattern, it is interesting to note that many of the cytokine profiles are in stark contrast to those found in studies without antigen sensitization or challenge. This highlights both the complexity of the immune system and the need for a balance between the different possible reactions such as the Th1 and Th2 responses. The fact that kefir can induce shifts in the immune system in both directions is promising as it may mean that the organisms in kefir are capable of regulating this balance in the immune system. This may be in part due to the increased number of regulatory T-cells observed in some of these studies, as regulatory T-cells play an important role in maintaining tolerance and supressing unnecessary inflammatory immune responses (Sakaguchi, 2011).

\section{HEALTH BENEFITS OF YEAST IN KEFIR}

As noted above, one unique characteristic of traditionally produced kefir relative to many other commercially produced fermented dairy products is the presence of a large population of yeast in both the kefir grain and in the fermented milk (Marsh et al., 2013). Although the majority of commercialized probiotic microbes are bacteria such as lactobacilli and bifidobacteria, there are some yeast species and strains that have been recognized to have probiotic properties, such as Saccharomyces boulardii
(Corthier et al., 1986; Czerucka et al., 2007). S. boulardii has been shown to improve the symptoms of Clostridium difficile associated diarrhea as well as reduce inflammation and alter the immune state and reactions in the gut, leading to its adoption as a treatment for C. difficile diarrhea (Buts et al., 1994; Castagliuolo et al., 1999; Kotowska et al., 2005; Villarruel et al., 2007).

Some yeasts from kefir have also shown immunomodulatory activities. For example K. marxianus B0399 has been shown to have the ability to adhere to Caco-2 cells (Maccaferri et al., 2012). When co-incubated with lipopolysaccharide (LPS) stimulated Caco-2 cells, a significant decrease in the secretion of IL-10, IL-12, IL-8, and IFN- $\gamma$ was observed (Maccaferri et al., 2012). Additionally, K. marxianus B0399 elicited a decrease in the secretion of pro-inflammatory cytokines TNF- $\alpha$, IL-6, and MIP$1 \alpha$ when co-incubated with PBMCs that had been stimulated with LPS (Maccaferri et al., 2012). This same study showed that in an in vitro colonic model system, $K$. marxianus was able to stably form a population in the model while simultaneously enhancing the levels of Bifidobacterium. Increases in the levels of the short chain fatty acids acetate and propionate were also observed. Utilizing a Caco-2 cell line with a ccl20 reporter gene, Romanin et al. (2010) were able to show that multiple yeast strains of S. cerevisiae (CIDCA 81109, 81106, 8112, 9127, 9123, 9136, 9133, 9124, 81103, 9132, 81108, 81102, 8175, and 8111), K. marxianus (CIDCA 81111, 8116, 8118, 81105, 8153, 8154, 8113, 81104, and 9121), and Issatchenkia spp. (CIDCA 9131) were able to inhibit the expression of the ccl20 reporter when incubated with the cells prior to stimulation with Salmonella flagellar protein FliC. From these yeasts, K. marxianus CIDCA 8154 was selected for further testing and showed the ability to inhibit the levels of ccl20 expression in Caco- 2 cells regardless of whether the stimulation came from FliC, IL- $1 \beta$, or TNF- $\alpha$. The strain also inhibited the expression of IL- 8 and MIP- $2 \alpha$ in HT-29 cells and inhibited ccl20 expression in a mouse ligated intestinal loop model when administered prior to stimulation with FliC (Romanin et al., 2010). Yeasts isolated from kefir have also shown the ability to improve the probiotic properties of bacterial species by improving the viability of these bacterial strains over time in simulated gastric and intestinal juice, and through improving the adhesion of LAB to Caco-2 cells in an in vitro model. This effect is likely due to the co-aggregation of the two microbial species (Xie et al., 2012).

\section{KEFIRAN AND THE CELL FREE FRACTION OF KEFIR}

In addition to the microbial populations present in kefir and other fermented probiotics, there are also fermentation products and other by-products of the metabolism of these microbes that possess bioactivity. Some of these by-products may have a profound effect on the host without the presence of the microbial population. Such a by-product is kefiran, the exopolysaccharide produced by L. kefiranofaciens during fermentation (Maeda et al., 2004b; Vinderola et al., 2006a). Mice fed kefiran dissolved in drinking water showed increases in the levels of $\operatorname{IgA}+\mathrm{B}$ cells, as well as increases in IL-6, IL-10, and IL-12 in the 
lamina propria of the small intestine after 7 days of feeding (Vinderola et al., 2006a). In a murine model of asthma using OVA sensitization, kefiran introduced intra-gastrically $1 \mathrm{~h}$ prior to challenge reduced levels of the Th2 cytokines IL- 4 and IL5 and lowered AHR when compared to OVA challenged mice that did not receive kefiran (Kwon et al., 2008). After the same period the study showed increases in serum levels of IL-4, IL-6, IL-10, and IFN- $\gamma$ (Kwon et al., 2008). Addition of kefiran to a co-incubation of $B$. cereus culture supernatant and Caco- 2 cell monolayer resulted in reduced cell detachment and greater mitochondrial activity, as well as negated the haemolytic effect of the $B$. cereus culture supernatant on human red blood cells (Medrano et al., 2008). Genetically diabetic (KKAy) mice fed kefiran were found to have decreasing levels of blood glucose throughout a 30 days examination while a control group was found to have constantly increasing and generally higher levels of blood glucose throughout the same timeline (Maeda et al., 2004a). Using SD rats as a model for constipation, it was also found that kefiran significantly improved the symptoms of constipation over the control group (Maeda et al., 2004a).

A water-soluble polysaccharide isolated from kefir grain (KGF-C) was shown to improve humoral immune response in mice against Sheep Red Blood Cells (SRBC). The levels of antiSRBC cells isolated from the spleen of mice immunized with SRBC while being intubated with KGF-C was significantly higher than in control mice 4 days post immunization (Murofushi et al., 1986). However, this effect was not seen in nu/nu mice (no thymus or $\mathrm{T}$ cell population) immunized with SRBC, or in conventional mice immunized with thymusindependent antigens, indicating that the mechanism of action is likely through the T cell population (Murofushi et al., 1986). Sphingomyelin isolated from kefir has been shown to increase IFN- $\beta$ secretion in human MG-63 cells when compared to commercial sphingomyelin and sphingosine (Osada et al., 1993).

Kefir cell-free supernatant (KCFS) has been shown to increase the levels of IFN- $\beta$, IL- 6 , IL-12, and TNF- $\alpha$ secreted by RAW 264.7 cells through a TLR2 dependent mechanism (Hong et al., 2009). Cell-free fractions of kefir have also been shown to increase the levels of these cytokines in peritoneal macrophages and adherent cells from the Peyer's patches of mice (Vinderola et al., 2006b). In addition, KCFSs were found to have a significant impact on tumor size, apoptosis, and immune recruitment in a murine breast cancer model, resulting in increased apoptosis of tumor cells and increases in the CD4 $+\mathrm{T}$ cell population (de Moreno de LeBlanc et al., 2007). In in vitro studies utilizing human T-lymphotropic virus 1 (HTLV-1) positive HuT-102 Malignant $\mathrm{T}$ lymphocytes as a model for $\mathrm{T}$ cell leukemia, the KCFS was found to inhibit proliferation by up to $98 \%$ while simultaneously decreasing the transcriptional levels of TGF$\alpha$. These effects have also been observed in HTLV-1 negative malignant T cells with the same decrease in TGF- $\alpha$ transcription being observed (Rizk et al., 2009; Maalouf et al., 2011). In addition to anti-proliferative effects, KCFS was found to induce apoptosis in both HTLV-1 positive and negative malignant T cells through the up regulation of bax and down regulation of $b c l-2$ in a dose dependent manner (Rizk et al., 2013).

\section{CONCLUSION}

The purpose of this review has been to collate and summarize that which is known about the microbial composition of kefir and how this composition plays a role in the health benefits associated with kefir consumption. Kefir is a dynamic fermented dairy product with many different factors affecting the benefits associated with its consumption. These factors include the variable yeast and bacterial species present, as well as metabolites such as kefiran and other exopolysaccharides. While kefir has been associated with health benefits for $100 \mathrm{~s}$ of years, the exact form of these benefits has, until recently, not been studied. The use of animal models and other in vitro analyses has allowed for the elucidation of how kefir positively impacts host health. Whole kefir, as well as specific fractions and individual organisms isolated from kefir, provide a multitude of positive effects when consumed. These range from improved cholesterol metabolism and wound healing, to the modulation of the immune system and microbiome, and even the potential alleviation of allergies and cancers. Further studies into the mechanisms behind these effects will allow scientists to better understand exactly how kefir and other fermented dairy products confer these benefits as well as how to harness these traits outside of kefir itself.

The wide range of potential health promoting effects of kefir could lead to a further expansion on the popularity of both traditional fermented kefir and products that are manufactured with kefir fractions or organisms. In order to fully exploit the beneficial characteristics of kefir, a more in-depth understanding of the composition of kefir is critical. With advances in metagenomic analysis through the development of high-throughput sequencing technology, this is a very realistic prospect. Armed with this knowledge, it should be possible to more readily isolate and examine the phenotypic characteristics of individual organisms present in a kefir blend while also providing a greater insight into the evolution of these organisms and how they became specialized to the kefir ecosystem. The additional knowledge gained can also provide crucial information relating to the mechanisms and exact agents responsible for beneficial effects that have been attributed to kefir (Atalan et al., 2003; Rodrigues et al., 2005; Huseini et al., 2012; Rahimzadeh et al., 2014).

The need for further research does not only apply to the mechanisms by which kefir consumption exerts these effects but also which organisms or parts of kefir are responsible for each benefit. By determining which organisms and metabolites are essential for each process, the possibility arises for the commercial manufacturing of kefir that is specifically designed to create the most profound effect in those that consume it. As it stands currently, the highly variable nature of the organisms and metabolites present in traditional kefir requires health claims to be verified individually in each grain and kefir beverage. The ability to combine the best possible strains of the best organisms from multiple sources of kefir would create the potential for greater benefits than have been previously observed, with a 
measure of control over these effects that has not been possible in traditional kefir.

\section{AUTHOR CONTRIBUTIONS}

$\mathrm{BB}$ wrote the review and compiled, figures, tables, and references. PC supervised, edited, and approved the review. BW supervised, edited, and approved the review.

\section{REFERENCES}

Altmann, S. W., Davis, H. R. Jr., Zhu, L. J., Yao, X., Hoos, L. M., Tetzloff, G., et al. (2004). Niemann-Pick C1 Like 1 protein is critical for intestinal cholesterol absorption. Science 303, 1201-1204. doi: 10.1126/science.1093131

Angulo, L., Lopez, E., and Lema, C. (1993). Microflora present in kefir grains of the Galician region (North-West of Spain). J. Dairy Res. 60, 263-267. doi: 10.1017/S002202990002759X

Assadi, M. M., Pourahmad, R., and Moazami, N. (2000). Use of isolated kefir starter cultures in kefir production. World J. Microbiol. Biotechnol. 16, 541-543. doi: 10.1023/A:1008939132685

Atalan, G., Demirkan, I., Yaman, H., and Cina, M. (2003). Effect of topical kefir application on open wound healing on in vivo study. Kafkas Univ. Vet. Fak. Dderg. 9, 43-47.

Azad, M. B., Konya, T., Maughan, H., Guttman, D. S., Field, C. J., Sears, M. R., et al. (2013). Infant gut microbiota and the hygiene hypothesis of allergic disease: impact of household pets and siblings on microbiota composition and diversity. Allergy Asthma Clin. Immunol. 9, 15. doi: 10.1186/1710-1492-9-15

Beena, A., and Prasad, V. (1997). Effect of yogurt and bifidus yogurt fortified with skim milk powder, condensed whey and lactose-hydrolysed condensed whey on serum cholesterol and triacylglycerol levels in rats. J. Dairy Res. 64, 453-457. doi: $10.1017 /$ S0022029997002252

Buts, J.-P., De Keyser, N., and De Raedemaeker, L. (1994). Saccharomyces boulardii enhances rat intestinal enzyme expression by endoluminal release of polyamines. Pediatr. Res. 36, 522-527. doi: 10.1203/00006450-199410000-00019

Carasi, P., Racedo, S., Jacquot, C., Romanin, D., Serradell, M., and Urdaci, M. (2015). Impact of Kefir Derived Lactobacillus kefiri on the mucosal immune response and gut microbiota. J. Immunol. Res. 2015, 361604. doi: $10.1155 / 2015 / 361604$

Castagliuolo, I., Riegler, M. F., Valenick, L., LaMont, J. T., and Pothoulakis, C. (1999). Saccharomyces boulardii protease inhibits the effects of Clostridium difficile toxins A and B in human colonic mucosa. Infect. Immun. 67, 302-307.

Cevikbas, A., Yemni, E., Ezzedenn, F. W., Yardimici, T., Cevikbas, U., and Stohs, S. (1994). Antitumoural antibacterial and antifungal activities of kefir and kefir grain. Phytother. Res. 8, 78-82. doi: 10.1002/ptr.2650080205

Chen, H.-C., Wang, S.-Y., and Chen, M.-J. (2008). Microbiological study of lactic acid bacteria in kefir grains by culture-dependent and culture-independent methods. Food Microbiol. 25, 492-501. doi: 10.1016/j.fm.2008.01.003

Chen, Y., Hsiao, P., Hong, W., Dai, T., and Chen, M. (2012). Lactobacillus kefiranofaciens M1 isolated from milk kefir grains ameliorates experimental colitis in vitro and in vivo. J. Dairy Sci. 95, 63-74. doi: 10.3168/jds.2011-4696

Chen, Y., Lee, T., Hong, W., Hsieh, H., and Chen, M. (2013). Effects of Lactobacillus kefiranofaciens M1 isolated from kefir grains on enterohemorrhagic Escherichia coli infection using mouse and intestinal cell models. J. Dairy Sci. 96, 7467-7477. doi: $10.3168 /$ jds.2013-7015

Chen, Y.-P., and Chen, M.-J. (2013). Effects of Lactobacillus kefiranofaciens M1 Isolated from kefir grains on germ-free mice. PLoS ONE 8:e78789. doi: 10.1371/journal.pone.0078789

Correa Franco, M., Golowczyc, M. A., De Antoni, G. L., Pérez, P. F., Humen, M., and de los Angeles Serradell, M. (2013). Administration of kefir-fermented milk protects mice against Giardia intestinalis infection. J. Med. Microbiol 62, 1815-1822. doi: 10.1099/jmm.0.068064-0

Corthier, G., Dubos, F., and Ducluzeau, R. (1986). Prevention of Clostridium difficile induced mortality in gnotobiotic mice by Saccharomyces boulardii. Can. J. Microbiol. 32, 894-896. doi: 10.1139/m86-164

\section{ACKNOWLEDGMENTS}

The authors are funded through the Teagasc Walsh Fellowship Scheme (2014025) and internal Teagasc funding (RMIS6486). BW is supported by the Canada Research Chairs Program and research in the Cotter laboratory is funded by SFI through the PI award "Obesibiotics" (11/PI/1137) and in the form of a center grant (APC Microbiome Institute Grant Number $\mathrm{SFI} / 12 / \mathrm{RC} / 2273)$.

Czerucka, D., Piche, T., and Rampal, P. (2007). Review article: yeast as probiotics-Saccharomyces boulardii. Aliment. Pharmacol. Ther. 26, 767-778. doi: 10.1111/j.1365-2036.2007.03442.x

de Moreno de LeBlanc, A., Matar, C., Farnworth, E., and Perdigon, G. (2006). Study of cytokines involved in the prevention of a murine experimental breast cancer by kefir. Cytokine 34, 1-8. doi: 10.1016/j.cyto.2006.03.008

de Moreno de LeBlanc, A., Matar, C., Farnworth, E., and Perdigon, G. (2007). Study of immune cells involved in the antitumor effect of kefir in a murine breast cancer model. J. Dairy Sci. 90, 1920-1928. doi: 10.3168/jds.2006-079

Diosma, G., Romanin, D. E., Rey-Burusco, M. F., Londero, A., and Garrote, G. L. (2014). Yeasts from kefir grains: isolation, identification, and probiotic characterization. World J. Microbiol. Biotechnol. 30, 43-53. doi: 10.1007/s11274013-1419-9

Dobson, A., O’Sullivan, O., Cotter, P. D., Ross, P., and Hill, C. (2011). Highthroughput sequence-based analysis of the bacterial composition of kefir and an associated kefir grain. FEMS Microbiol. Lett. 320, 56-62. doi: 10.1111/j.15746968.2011.02290.x

Frengova, G. I., Simova, E. D., Beshkova, D. M., and Simov, Z. I. (2002). Exopolysaccharides produced by lactic acid bacteria of kefir grains. Z. Naturforsch. C 57, 805-810.

Gao, J., Gu, F., Ruan, H., Chen, Q., He, J., and He, G. (2013). Induction of apoptosis of gastric cancer cells SGC7901 in vitro by a cell-free fraction of Tibetan kefir. Int. Dairy J. 30, 14-18. doi: 10.1016/j.idairyj.2012.11.011

Garofalo, C., Osimani, A., Milanović, V., Aquilanti, L., De Filippis, F., Stellato, G., et al. (2015). Bacteria and yeast microbiota in milk kefir grains from different Italian regions. Food Microbiol. 49, 123-133. doi: 10.1016/j.fm.2015. 01.017

Garrote, G. L., Abraham, A. G., and De Antoni, G. L. (2001). Chemical and microbiological characterisation of kefir grains. J. Dairy Res. 68, 639-652. doi: 10.1017/S0022029901005210

Ghoneum, M., and Gimzewski, J. (2014). Apoptotic effect of a novel kefir product, PFT, on multidrug-resistant myeloid leukemia cells via a hole-piercing mechanism. Int. J. Oncol. 44, 830-837. doi: 10.3892/ijo.2014.2258

Golowczyc, M. A., Gugliada, M. J., Hollmann, A., Delfederico, L., Garrote, G. L., Abraham, A. G., et al. (2008). Characterization of homofermentative Lactobacilli isolated from kefir grains: potential use as probiotic. J. Dairy Res. 75, 211-217. doi: 10.1017/S0022029908003117

Güzel-Seydim, Z., Seydim, A., Greene, A., and Bodine, A. (2000). Determination of organic acids and volatile flavor substances in kefir during fermentation. J. Food Composit. Anal. 13, 35-43. doi: 10.1006/jfca.1999.0842

Guzel-Seydim, Z., Seydim, A., Greene, A., and Taş, T. (2006). Determination of antimutagenic properties of acetone extracted fermented milks and changes in their total fatty acid profiles including conjugated linoleic acids. Int. J. Dairy Technol. 59, 209-215. doi: 10.1111/j.1471-0307.2006.00265.x

Hamet, M. F., Londero, A., Medrano, M., Vercammen, E., Van Hoorde, K., Garrote, G. L., et al. (2013). Application of culture-dependent and cultureindependent methods for the identification of Lactobacillus kefiranofaciens in microbial consortia present in kefir grains. Food Microbiol. 36, 327-334. doi: 10.1016/j.fm.2013.06.022

Hamet, M. F., Medrano, M., Pérez, P. F., and Abraham, A. G. (2016). Oral administration of kefiran exerts a bifidogenic effect on BALB/c mice intestinal microbiota. Benef. Microbes 7, 237-246. doi: 10.3920/BM2015.0103

Hill, C., Guarner, F., Reid, G., Gibson, G. R., Merenstein, D. J., Pot, B., et al. (2014). Expert consensus document: the international scientific association for probiotics and prebiotics consensus statement on the scope and appropriate 
use of the term probiotic. Nat. Rev. Gastroenterol. Hepatol. 11, 506-514. doi: 10.1038/nrgastro.2014.66

Hong, W.-S., Chen, H.-C., Chen, Y.-P., and Chen, M.-J. (2009). Effects of kefir supernatant and lactic acid bacteria isolated from kefir grain on cytokine production by macrophage. Int. Dairy J. 19, 244-251. doi: 10.1016/j.idairyj.2008.10.010

Hong, W.-S., Chen, Y.-P., and Chen, M.-J. (2010). The antiallergic effect of kefir Lactobacilli. J. Food Sci. 75, H244-H253. doi: 10.1111/j.1750-3841.2010. 01787.x

Hong, W.-S., Chen, Y.-P., Dai, T.-Y., Huang, I.-N., and Chen, M.-J. (2011). Effect of heat-inactivated kefir-isolated Lactobacillus kefiranofaciens M1 on preventing an allergic airway response in mice. J. Agric. Food Chem. 59, 9022-9031. doi: $10.1021 /$ jf201913x

Huang, Y., Wang, X., Wang, J., Wu, F., Sui, Y., Yang, L., et al. (2013a). Lactobacillus plantarum strains as potential probiotic cultures with cholesterol-lowering activity. J. Dairy Sci. 96, 2746-2753. doi: 10.3168/jds.2012-6123

Huang, Y., Wu, F., Wang, X., Sui, Y., Yang, L., and Wang, J. (2013b). Characterization of Lactobacillus plantarum Lp27 isolated from tibetan kefir grains: a potential probiotic bacterium with cholesterol-lowering effects. J. Dairy Sci. 96, 2816-2825. doi: 10.3168/jds.2012-6371

Hugo, A., Kakisu, E., De Antoni, G., and Perez, P. (2008). Lactobacilli antagonize biological effects of enterohaemorrhagic Escherichia coli in vitro. Lett. Appl. Microbiol. 46, 613-619. doi: 10.1111/j.1472-765X.2008.02363.x

Huseini, H. F., Rahimzadeh, G., Fazeli, M. R., Mehrazma, M., and Salehi, M. (2012). Evaluation of wound healing activities of kefir products. Burns 38, 719-723. doi: 10.1016/j.burns.2011.12.005

Iraporda, C., Romanin, D. E., Rumbo, M., Garrote, G. L., and Abraham, A. G. (2014). The role of lactate on the immunomodulatory properties of the nonbacterial fraction of kefir. Food Res. Int. 62, 247-253. doi: 10.1016/j.foodres.2014.03.003

Ismail, A. A., El-Nockrashy, S. A., and Khorshid, M. (1983). A beverage from separated buffalo milk fermented with kefir grains. Int. J. Dairy Technol. 36, 117-118. doi: 10.1111/j.1471-0307.1983.tb02230.x

Kakisu, E., Abraham, A. G., Tironi Farinati, C., Ibarra, C., and De Antoni, G. L. (2013). Lactobacillus plantarum isolated from kefir protects vero cells from cytotoxicity by type-II shiga toxin from Escherichia coli O157: H7. J. Dairy Res. 80, 64-71. doi: 10.1017/S0022029912000659

Kakisu, E. J., Abraham, A. G., Perez, P. F., and De Antoni, G. L. (2007). Inhibition of Bacillus cereus in milk fermented with kefir grains. J. Food Protect. 70, 2613-2616.

Kirjavainen, P., Arvola, T., Salminen, S., and Isolauri, E. (2002). Aberrant composition of gut microbiota of allergic infants: a target of bifidobacterial therapy at weaning? Gut 51, 51-55. doi: 10.1136/gut.51.1.51

Korsak, N., Taminiau, B., Leclercq, M., Nezer, C., Crevecoeur, S., Ferauche, C., et al. (2015). Short communication: evaluation of the microbiota of kefir samples using metagenetic analysis targeting the $16 \mathrm{~S}$ and $26 \mathrm{~S}$ ribosomal DNA fragments. J. Dairy Sci. 98, 3684-3689. doi: 10.3168/jds.2014-9065

Kotowska, M., Albrecht, P., and Szajewska, H. (2005). Saccharomyces boulardii in the prevention of antibiotic-associated diarrhoea in children: a randomized double-blind placebo-controlled trial. Aliment. Pharmacol. Ther. 21, 583-590. doi: 10.1111/j.1365-2036.2005.02356.x

Kwon, O.-K., Ahn, K.-S., Lee, M.-Y., Kim, S.-Y., Park, B.-Y., Kim, M.-K., et al. (2008). Inhibitory effect of kefiran on ovalbumin-induced lung inflammation in a murine model of asthma. Arch. Pharm. Res. 31, 1590-1596. doi: 10.1007/s12272-001-2156-4

La Rivière, J., Kooiman, P., and Schmidt, K. (1967). Kefiran, a novel polysaccharide produced in the kefir grain by Lactobacillus brevis. Arch. Mikrobiol. 59, 269-278. doi: 10.1007/BF00406340

Latorre-García, L., del Castillo-Agudo, L., and Polaina, J. (2007). Taxonomical classification of yeasts isolated from kefir based on the sequence of their ribosomal RNA genes. World J. Microbiol. Biotechnol. 23, 785-791. doi: 10.1007/s11274-006-9298-y

Lee, M.-Y., Ahn, K.-S., Kwon, O.-K., Kim, M.-J., Kim, M.-K., Lee, I.-Y., et al. (2007). Anti-inflammatory and anti-allergic effects of kefir in a mouse asthma model. Immunobiology 212, 647-654. doi: 10.1016/j.imbio.2007.05.004

Leite, A., Miguel, M., Peixoto, R., Ruas-Madiedo, P., Paschoalin, V., Mayo, B., et al. (2015). Probiotic potential of selected lactic acid bacteria strains isolated from Brazilian kefir grains. J. Dairy Sci. 98, 3622-3632. doi: 10.3168/jds.2014-9265
Leite, A. M. O., Mayo, B., Rachid, C. T. C. C., Peixoto, R. S., Silva, J. T., Paschoalin, V. M. F., et al. (2012). Assessment of the microbial diversity of Brazilian kefir grains by PCR-DGGE and pyrosequencing analysis. Food Microbiol. 31, 215-221. doi: 10.1016/j.fm.2012.03.011

Li, L., Wieme, A., Spitaels, F., Balzarini, T., Nunes, O. C., Manaia, C. M., et al. (2014). Acetobacter sicerae sp. nov., isolated from cider and kefir, and identification of species of the genus Acetobacter by dnaK, groEL and rpoB sequence analysis. Int. J. Syst. Evol. Microbiol. 64, 2407-2415. doi: 10.1099/ijs.0.058354-0

Likotrafiti, E., Valavani, P., Argiriou, A., and Rhoades, J. (2015). In vitro evaluation of potential antimicrobial synbiotics using Lactobacillus kefiri isolated from kefir grains. Int. Dairy J. 45, 23-30. doi: 10.1016/j.idairyj.2015.01.013

Liu, H., Xie, Y. H., Xiong, L. X., Dong, R. T., Pan, C. L., Teng, G. X., et al. (2012). Effect and (mechanism )of cholesterol-lowering by kluyveromyces from tibetan kefir. Adv. Mater. Res. 343-344, 1290-1298.

Liu, J.-R., Wang, S.-Y., Chen, M.-J., Chen, H.-L., Yueh, P.-Y., and Lin, C.W. (2006a). Hypocholesterolaemic effects of milk-kefir and soyamilk-kefir in cholesterol-fed hamsters. Br. J. Nutr. 95, 939-946. doi: 10.1079/BJN20061752

Liu, J. R., Wang, S. Y., Chen, M. J., Yueh, P. Y., and Lin, C. W. (2006b). The anti-allergenic properties of milk kefir and soymilk kefir and their beneficial effects on the intestinal microflora. J. Sci. Food Agric. 86, 2527-2533. doi: 10.1002/jsfa.2649

Maalouf, K., Baydoun, E., and Rizk, S. (2011). Kefir induces cell-cycle arrest and apoptosis in HTLV-1-negative malignant T-lymphocytes. Cancer Manag. Res. 3:39. doi: 10.2147/CMR.S15109

Maccaferri, S., Klinder, A., Brigidi, P., Cavina, P., and Costabile, A. (2012). Potential probiotic Kluyveromyces marxianus B0399 modulates the immune response in Caco-2 cells and peripheral blood mononuclear cells and impacts the human gut microbiota in an in vitro colonic model system. Appl. Environ. Microbiol. 78, 956-964. doi: 10.1128/AEM.06385-11

Maeda, H., Zhu, X., Omura, K., Suzuki, S., and Kitamura, S. (2004a). Effects of an exopolysaccharide (kefiran) on lipids, blood pressure, blood glucose, and constipation. Biofactors 22, 197-200. doi: 10.1002/biof.5520220141

Maeda, H., Zhu, X., Suzuki, S., Suzuki, K., and Kitamura, S. (2004b). Structural characterization and biological activities of an exopolysaccharide kefiran produced by Lactobacillus kefiranofaciens WT-2BT. J. Agric. Food Chem. 52, 5533-5538. doi: 10.1021/jf049617g

Mainville, I., Robert, N., Lee, B., and Farnworth, E. R. (2006). Polyphasic characterization of the lactic acid bacteria in kefir. Syst. Appl. Microbiol. 29, 59-68. doi: 10.1016/j.syapm.2005.07.001

Marquina, D., Santos, A., Corpas, I., Munoz, J., Zazo, J., and Peinado, J. (2002). Dietary influence of kefir on microbial activities in the mouse bowel. Lett. Appl. Microbiol. 35, 136-140. doi: 10.1046/j.1472-765X.2002. 01155.x

Marsh, A. J., O'Sullivan, O., Hill, C., Ross, R. P., and Cotter, P. D. (2013). Sequencing-based analysis of the bacterial and fungal composition of kefir grains and milks from multiple sources. PLoS ONE 8:e69371. doi: 10.1371/journal.pone.0069371

Medrano, M., Pérez, P. F., and Abraham, A. G. (2008). Kefiran antagonizes cytopathic effects of Bacillus cereus extracellular factors. Int. J. Food Microbiol. 122, 1-7. doi: 10.1016/j.ijfoodmicro.2007.11.046

Metchnikoff, E. (1908). The Prolongation of Life. New York, NY: Putnam.

Miao, J., Guo, H., Ou, Y., Liu, G., Fang, X., Liao, Z., et al. (2014). Purification and characterization of bacteriocin F1, a novel bacteriocin produced by Lactobacillus paracasei subsp. tolerans FX-6 from Tibetan kefir, a traditional fermented milk from Tibet, China. Food Control 42, 48-53. doi: 10.1016/j.foodcont.2014.01.041

Miguel, M. G. D. C. P., Cardoso, P. G., de Assis Lago, L., and Schwan, R. F. (2010). Diversity of bacteria present in milk kefir grains using culturedependent and culture-independent methods. Food Res. Int. 43, 1523-1528. doi: 10.1016/j.foodres.2010.04.031

Motaghi, M., Mazaheri, M., Moazami, N., Farkhondeh, A., Fooladi, M., and Goltapeh, E. (1997). Kefir production in Iran. World J. Microbiol. Biotechnol. 13, 579-581. doi: 10.1023/A:1018577728412

Murofushi, M., Mizuguchi, J., Aibara, K., and Matuhasi, T. (1986). Immunopotentiative effect of polysaccharide from kefir grain, KGF$\mathrm{C}$, administered orally in mice. Immunopharmacology 12, 29-35. doi: 10.1016/0162-3109(86)90049-4 
Nalbantoglu, U., Cakar, A., Dogan, H., Abaci, N., Ustek, D., Sayood, K., et al. (2014). Metagenomic analysis of the microbial community in kefir grains. Food Microbiol. 41, 42-51. doi: 10.1016/j.fm.2014.01.014

Osada, K., Nagira, K., Teruya, K., Tachibana, H., Shirahata, S., and Murakami, H. (1993). Enhancement of interferon-beta production with sphingomyelin from fermented milk. Biotherapy 7, 115-123. doi: 10.1007/BF01877735

Parvez, S., Malik, K. A., Ah Kang, S., and Kim, H. Y. (2006). Probiotics and their fermented food products are beneficial for health. J. Appl. Microbiol. 100, 1171-1185. doi: 10.1111/j.1365-2672.2006.02963.x

Pintado, M. E., Da Silva, J. A. L., Fernandes, P. B., Malcata, F. X., and Hogg, T. A. (1996). Microbiological and rheological studies on Portuguese kefir grains. Int. J. Food Sci. Technol. 31, 15-26. doi: 10.1111/j.1365-2621.1996. 16-316.x

Powell, J. E., Witthuhn, R. C., Todorov, S. D., and Dicks, L. M. T. (2007), Characterization of bacteriocin ST8KF produced by a kefir isolate Lactobacillus plantarum ST8KF. Int. Dairy J. 17, 190-198. doi: 10.1016/j.idairyj.2006. 02.012

Quiros, A., Hernandez-Ledesma, B., Ramos, M., Amigo, L., and Recio, I. (2005). Angiotensin-converting enzyme inhibitory activity of peptides derived from caprine kefir. J. Dairy Sci 88, 3480-3487. doi: 10.3168/jds.S00220302(05)73032-0

Rahimzadeh, G., Seyedi Dolatabad, S., and Fallah Rostami, F. (2014). Comparison of two types of gels in improving burn wound. Crescent J. Med. Biol. Sci. 1, 28-32.

Rea, M., Lennartsson, T., Dillon, P., Drinan, F., Reville, W., Heapes, M., et al. (1996). Irish kefir-like grains: their structure, microbial composition and fermentation kinetics. J. Appl. Bacteriol. 81, 83-94. doi: 10.1111/j.13652672.1996.tb03286.x

Rea, M. C., Clayton, E., O'Connor, P. M., Shanahan, F., Kiely, B., Ross, R. P., et al. (2007). Antimicrobial activity of lacticin 3,147 against clinical Clostridium difficile strains. J. Med. Microbiol. 56, 940-946. doi: 10.1099/jmm.0.47085-0

Rimada, P. S., and Abraham, A. G. (2006). Kefiran improves rheological properties of glucono- $\delta$-lactone induced skim milk gels. Int. Dairy J. 16, 33-39. doi: 10.1016/j.idairyj.2005.02.002

Rizk, S., Maalouf, K., and Baydoun, E. (2009). The antiproliferative effect of kefir cell-free fraction on HuT-102 malignant T lymphocytes. Clin. Lymphoma Myeloma 9(Suppl. 3), S198-S203. doi: 10.3816/CLM.2009.s.012

Rizk, S., Maalouf, K., Nasser, H., and El-Hayek, S. (2013). The Pro-apoptotic effect of kefir in Malignant T-lymphocytes Involves a p53 Dependent Pathway. Clin. Lymphoma Myeloma Leukemia 13(Suppl. 2), S367. doi: 10.1016/j.clml.2013.07.062

Rodrigues, K. L., Caputo, L. R., Carvalho, J. C., Evangelista, J., and Schneedorf, J. M. (2005). Antimicrobial and healing activity of kefir and kefiran extract. Int. J. Antimicrob. Agents 25, 404-408. doi: 10.1016/j.ijantimicag.2004.09.020

Romanin, D., Serradell, M., Gonzalez Maciel, D., Lausada, N., Garrote, G. L., and Rumbo, M. (2010). Down-regulation of intestinal epithelial innate response by probiotic yeasts isolated from kefir. Int. J. Food Microbiol. 140, 102-108. doi: 10.1016/j.ijfoodmicro.2010.04.014

Russell, S. L., Gold, M. J., Hartmann, M., Willing, B. P., Thorson, L., Wlodarska, M., et al. (2012). Early life antibiotic-driven changes in microbiota enhance susceptibility to allergic asthma. EMBO Rep. 13, 440-447. doi: 10.1038/embor.2012.32

Ryan, M. P., Rea, M. C., Hill, C., and Ross, R. P. (1996). An application in cheddar cheese manufacture for a strain of Lactococcus lactis producing a novel broad-spectrum bacteriocin, lacticin 3147. Appl. Environ. Microbiol. 62, 612-619.

Sakaguchi, S. (2011). Regulatory T cells: history and perspective. Methods Mol. Biol. 707, 3-17. doi: 10.1007/978-1-61737-979-6_1

Santos, A., San Mauro, M., Sanchez, A., Torres, J. M., and Marquina, D. (2003). The antimicrobial properties of different strains of Lactobacillus spp. isolated from kefir. Syst. Appl. Microbiol. 26, 434-437. doi: 10.1078/072320203322497464

Serafini, F., Turroni, F., Ruas-Madiedo, P., Lugli, G. A., Milani, C., Duranti, S., et al. (2014). Kefir fermented milk and kefiran promote growth of Bifidobacterium bifidum PRL2010 and modulate its gene expression. Int. J. Food Microbiol. 178, 50-59. doi: 10.1016/j.ijfoodmicro.2014.02.024

Sibel Akalin, A., Gönç, S., and Düzel, S. (1997). Influence of yogurt and acidophilus yogurt on serum cholesterol levels in mice. J. Dairy Sci. 80, 2721-2725. doi: $10.3168 /$ jds.S0022-0302(97)76233-7
Simova, E., Beshkova, D., Angelov, A., Hristozova, T., Frengova, G., and Spasov, Z. (2002). Lactic acid bacteria and yeasts in kefir grains and kefir made from them. J. Ind. Microbiol. Biotechnol. 28, 1-6. doi: 10.1038/sj/jim/7000186

Sjogren, Y. M., Jenmalm, M. C., Bottcher, M. F., Bjorksten, B., and SverremarkEkstrom, E. (2009). Altered early infant gut microbiota in children developing allergy up to 5 years of age. Clin. Exp. Allergy 39, 518-526. doi: 10.1111/j.13652222.2008.03156.x

Sorenson, C. M. (2004). Bcl-2 family members and disease. Biochim. Biophys. Acta 1644, 169-177. doi: 10.1016/j.bbamcr.2003.08.010

St-Onge, M. P., Farnworth, E. R., Savard, T., Chabot, D., Mafu, A., and Jones, P. J. (2002). Kefir consumption does not alter plasma lipid levels or cholesterol fractional synthesis rates relative to milk in hyperlipidemic men: a randomized controlled trial [ISRCTN10820810]. BMC Complement. Altern. Med. 2:1. doi: $10.1186 / 1472-6882-2-1$

Takizawa, S., Kojima, S., Tamura, S., Fujinaga, S., Benno, Y., and Nakase, T. (1994). Lactobacillus kefirgranum sp. nov. and Lactobacillus parakefir sp. nov., two new species from kefir grains. Int. J. Syst. Evol. Microbiol. 44, 435-439.

Tamang, J. P., Holzapfel, W. H., and Watabane, K. (2016). Review: diversity of microorganisms in global fermented foods and beverages. Front. Microbiol. 7:377. doi: $10.3389 /$ fmicb.2016.00377

Tamime, A. Y. (2002). Fermented milks: a historical food with modern applications-a review. Eur. J. Clin. Nutr. 56(Suppl. 4), S2-S15. doi: $10.1038 /$ sj.ejcn. 1601657

Tanabe, S. (2008). Analysis of food allergen structures and development of foods for allergic patients. Biosci. Biotechnol. Biochem. 72, 649-659. doi: 10.1271/bbb.70708

Taş, T. K., Ekinci, F. Y., and Guzel-Seydim, Z. B. (2012). Identification of microbial flora in kefir grains produced in Turkey using PCR. Int. J. Dairy Technol. 65, 126-131. doi: 10.1111/j.1471-0307.2011.00733.x

Thoreux, K., and Schmucker, D. L. (2001). Kefir milk enhances intestinal immunity in young but not old rats. J. Nutr. 131, 807-812.

Tsai, C.-C., Ke, P.-C., Hsu, T.-K., and Hsieh, Y.-M. (2012). Oral administration of multiple lactic acid bacteria strains suppressed allergic responses $\operatorname{IgE}$ in an ovalbumin-induced allergy BALB/c mouse model. Afr. J. Microbiol. Res. 6, 1206-1212.

Turroni, F., Serafini, F., Foroni, E., Duranti, S., Motherway, M. O. C., Taverniti, V., et al. (2013). Role of sortase-dependent pili of Bifidobacterium bifidum PRL2010 in modulating bacterium-host interactions. Proc. Natl. Acad. Sci. U.S.A. 110, 11151-11156. doi: 10.1073/pnas.1303897110

Urdaneta, E., Barrenetxe, J., Aranguren, P., Irigoyen, A., Marzo, F., and Ibáñez, F. C. (2007). Intestinal beneficial effects of kefir-supplemented diet in rats. Nutr. Res. 27, 653-658. doi: 10.1016/j.nutres.2007.08.002

Vardjan, T., Lorbeg, P. M., Rogelj, I., and Majhenič, A. Č (2013). Characterization and stability of Lactobacilli and yeast microbiota in kefir grains. J. Dairy Sci. 96, 2729-2736. doi: 10.3168/jds.2012-5829

Villarruel, G., Rubio, D. M., Lopez, F., Cintioni, J., Gurevech, R., Romero, G., et al. (2007). Saccharomyces boulardii in acute childhood diarrhoea: a randomized, placebo-controlled study. Acta Paediatr. 96, 538-541. doi: 10.1111/j.16512227.2007.00191.x

Vinderola, C. G., Duarte, J., Thangavel, D., Perdigón, G., Farnworth, E., and Matar, C. (2005). Immunomodulating capacity of kefir. J. Dairy Res. 72, 195202. doi: $10.1017 / S 0022029905000828$

Vinderola, G., Perdigón, G., Duarte, J., Farnworth, E., and Matar, C. (2006a). Effects of the oral administration of the exopolysaccharide produced by Lactobacillus kefiranofaciens on the gut mucosal immunity. Cytokine 36, 254-260. doi: 10.1016/j.cyto.2007.01.003

Vinderola, G., Perdigon, G., Duarte, J., Thangavel, D., Farnworth, E., and Matar, C. (2006b). Effects of kefir fractions on innate immunity. Immunobiology 211, 149-156. doi: 10.1016/j.imbio.2005.08.005

Vujičić, I., Vulič, M., and Könyves, T. (1992). Assimilation of cholesterol in milk by kefir cultures. Biotechnol. Lett. 14, 847-850. doi: 10.1007/BF01 029151

Wang, S.-Y., Chen, H.-C., Liu, J.-R., Lin, Y.-C., and Chen, M.-J. (2008). Identification of yeasts and evaluation of their distribution in Taiwanese kefir and viili starters. J. Dairy Sci. 91, 3798-3805. doi: 10.3168/jds.2007-0468

Wang, S.-Y., Chen, K.-N., Lo, Y.-M., Chiang, M.-L., Chen, H.-C., Liu, J.-R., et al. (2012). Investigation of microorganisms involved in biosynthesis of the kefir grain. Food Microbiol. 32, 274-285. doi: 10.1016/j.fm.2012.07.001 
Wang, Y., Xu, N., Xi, A., Ahmed, Z., Zhang, B., and Bai, X. (2009). Effects of Lactobacillus plantarum MA2 isolated from Tibet kefir on lipid metabolism and intestinal microflora of rats fed on high-cholesterol diet. Appl. Microbiol. Biotechnol. 84, 341-347. doi: 10.1007/s00253-009-2012-x

West, C. E. (2014). Gut microbiota and allergic disease: new findings. Curr. Opin. Clin. Nutr. Metab. Care 17, 261-266. doi: 10.1097/MCO.0000000000000044

WHO (1982). Prevention of coronary heart disease. World Health Organ. Tech. Rep. Ser. 678, 1-53.

Witthuhn, R., Schoeman, T., and Britz, T. (2005). Characterisation of the microbial population at different stages of Kefir production and Kefir grain mass cultivation. Int. Dairy J. 15, 383-389. doi: 10.1016/j.idairyj.2004.07.016

Witthuhn, R. C., Schoeman, T., and Britz, T. J. (2004). Isolation and characterization of the microbial population of different South African kefir grains. Int. J. Dairy Technol. 57, 33-37. doi: 10.1111/j.1471-0307.2004.00126.x

Wolever, T., Spadafora, P. J., Cunnane, S. C., and Pencharz, P. B. (1995). Propionate inhibits incorporation of colonic $[1,2-13 \mathrm{C}]$ acetate into plasma lipids in humans. Am. J. Clin. Nutr. 61, 1241-1247.

Wood, R. A. (2003). The natural history of food allergy. Pediatrics 111, 1631-1637.

Wszolek, M., Tamime, A., Muir, D., and Barclay, M. (2001). Properties of kefir made in Scotland and Poland using bovine, caprine and ovine milk with different starter cultures. LWT-Food Sci. Technol. 34, 251-261. doi: 10.1006/fstl.2001.0773

Xiao, J., Kondo, S., Takahashi, N., Miyaji, K., Oshida, K., Hiramatsu, A., et al. (2003). Effects of milk products fermented by Bifidobacterium longum on blood lipids in rats and healthy adult male volunteers. J. Dairy Sci. 86, 2452-2461. doi: 10.3168/jds.S0022-0302(03)73839-9

Xie, N., Zhou, T., and Li, B. (2012). Kefir yeasts enhance probiotic potentials of Lactobacillus paracasei H9: the positive effects of coaggregation between the two strains. Food Res. Int. 45, 394-401. doi: 10.1016/j.foodres.2011.10.045

Yazdanbakhsh, M., Kremsner, P. G., and van Ree, R. (2002). Allergy, parasites, and the hygiene hypothesis. Science 296, 490-494. doi: 10.1126/science.296.5567.490

Yoshida, Y., Yokoi, W., Ohishi, K., Ito, M., Naito, E., and Sawada, H. (2005). Effects of the cell wall of Kluyveromyces marxianus YIT 8292 on the plasma cholesterol and fecal sterol excretion in rats fed on a high-cholesterol diet. Biosci. Biotechnol. Biochem. 69, 714-723. doi: 10.1271/bbb.69.714

Yüksekdağ, Z., Beyatli, Y., and Aslim, B. (2004). Determination of some characteristics coccoid forms of lactic acid bacteria isolated from Turkish kefirs with natural probiotic. J. WT-Food Sci. Technol. 37, 663-667. doi: 10.1016/j.lwt.2004.02.004

Zanirati, D. F., Abatemarco, M., de Cicco Sandes, S. H., Nicoli, J. R., Nunes, ÁC., and Neumann, E. (2015). Selection of lactic acid bacteria from Brazilian kefir grains for potential use as starter or probiotic cultures. Anaerobe 32, 70-76. doi: 10.1016/j.anaerobe.2014.12.007

Zheng, Y., Lu, Y., Wang, J., Yang, L., Pan, C., and Huang, Y. (2013). Probiotic properties of Lactobacillus strains isolated from Tibetan kefir grains. PLoS ONE 8:e69868. doi: 10.1371/journal.pone. 0069868

Zhou, J., Liu, X., Jiang, H., and Dong, M. (2009). Analysis of the microflora in Tibetan kefir grains using denaturing gradient gel electrophoresis. Food Microbiol. 26, 770-775. doi: 10.1016/j.fm.2009. 04.009

Zhuang, G., Liu, X.-M., Zhang, Q.-X., Tian, F.-W., Zhang, H., Zhang, H.-P., et al. (2012). Research advances with regards to clinical outcome and potential mechanisms of the cholesterol-lowering effects of probiotics. Clin. Lipidol. 7 , 501-507. doi: 10.2217/clp.12.40

Conflict of Interest Statement: The authors declare that the research was conducted in the absence of any commercial or financial relationships that could be construed as a potential conflict of interest.

Copyright (c) 2016 Bourrie, Willing and Cotter. This is an open-access article distributed under the terms of the Creative Commons Attribution License (CC BY). The use, distribution or reproduction in other forums is permitted, provided the original author(s) or licensor are credited and that the original publication in this journal is cited, in accordance with accepted academic practice. No use, distribution or reproduction is permitted which does not comply with these terms. 